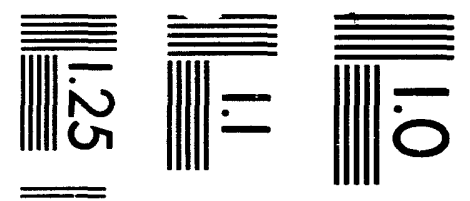

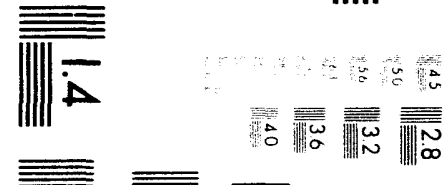

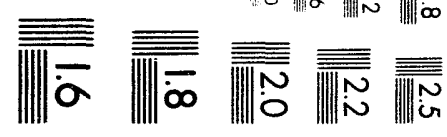



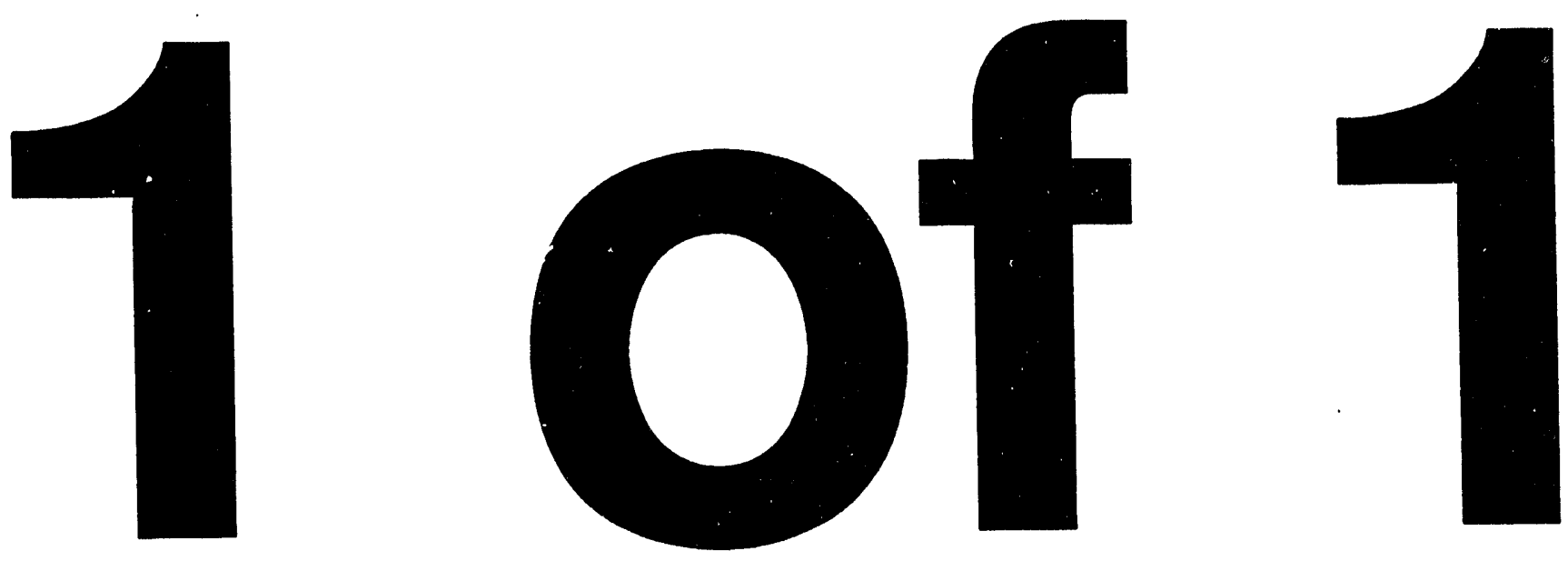
Measurement of Unsaturated Hydraulic

Conductivity and Chemical Transport

in Yucca Mountain Tuff

Milestone Report 3044-WBS1.2.3.4.1.4.1

James L. Conca* 


\title{
MEASUREMENT OF UNSATURATED HYDRAULIC CONDUCTIVITY AND CHEMICAL TRANSPORT IN YUCCA MOUNTAIN TUFF MILESTONE REPORT 3044-WBS1.2.3.4.1.4.1
}

\author{
by
}

James L. Conca

\begin{abstract}
Hydraulic conductivities, $K$, were experimentally determined as a function of volumetric water content, $\theta$, in tuff from the Yucca Mountain site. In addition, the retardation factor, $R_{f}$, in Yucca Mountain tuff with respect to selenium, as the selenite species, was measured under unsaturated conditions. These data were used to determine the feasibility of applying a new unsaturated flow technology (UFA ${ }^{\mathrm{TM}}$ ) to further hydrologic studies at Yucca Mountain. The UFA directly measures $K(\theta)$ rapidly in Yucca Mountain tuff and is shown to agree well with traditional methods. Hysteresis does not appear important during this testing. Hydraulic steadystate is achieved fastest during desaturation from a saturated state. Imbibition into dry tuff requires a long time for steadystate to occur because of slow filling of the diffusion porosity which can take a few weeks. The existing UFA is a prototype, and a new design of the next generation UFA is completed that eliminates some of the earlier problems. These preliminary investigations demonstrate that the UFA is a useful investigative technique that should be used to compliment existing techniques for hydrogeochemical characterization at Yucca Mountain and other arid sites.
\end{abstract}

\section{INTRODUCTION}

The scope of this report is four-fold: 1) to determine the feasibility of a new unsaturated flow technology in measuring unsaturated hydraulic conductivity in Yucca Mountain tuff as an additional tool for characterizing hydrologic properties, 2) to compare this method to existing methods for estimating hydraulic conductivity in the unsaturated zone, 3) to review 
hydraulic conductivities determined for tuff from Yucca Mountain using this method, and 4) to determine the feasibility of using the UFA for hydrogeochemical characterization as in the measurement of $R_{f}$.

Modeling the transport of contaminants in vadose zones surrounding nuclear and hazardous waste repositories requires knowledge of the material characteristics under unsaturated conditions. The hydraulic conductivity, $K$, retardation factor, $R_{f}$, and diffusion coefficient, $D$, are the primary transport parameters that are key input parameters to existing and developing models of contaminant release from repository systems and waste sites (Pigford and Chambré, 1988). Knowledge of $K, R_{f}$, and $D$, as a function of the volumetric water content, referred to as the characteristic behaviors of a porous medium, is particularly important in the near-field transition zone around high-level waste packages where changes in temperature, water content, compaction of backfill, infiltration of fines, and secondary mineralization will alter transport characteristics. An excellent discussion of transport parameters, processes, and mechanisms in partially saturated media can be found in Wang and Narasimhan, 1993.

However, transport parameters have generally been difficult to obtain as a function of the volumetric water content. Traditional methods of investigating unsaturated systems require very long times to attain homogeneous distributions of water because normal gravity does not provide a large enough driving force relative to the low hydraulic conductivities that characterize unsaturated conditions. The low conductivities of fractured whole rock under normal potential gradients have hampered experimental studies because of the long time scales required for the experiments. Most of the existing transport data on fractured rock comes from saturated flow studies using high pressures that reduce experimental times but lose the natural conditions by inducing new fractures, enlarging existing fractures, and affecting pressure-dependent reactions and phase stabilities. In situ measurements of unsaturated flow in whole rock in boreholes or at the surface using surface infiltrometers have provided some excellent results (Kilbury, et al. 1986), but are restricted to a narrow range of water contents, and the boreholes themselves can severely disturb the system (Montazer, 1987). Lin and co-workers at Lawrence Livermore National Laboratory (Lin and Daily, 1984) have shown that computed impedance tomography (CIT) has great promise in the study of unsaturated flow, but CIT still has only coarse resolution and is not developed for aqueous chemical studies. Yang and co-workers at the United States Geological Survey Denver have extracted pore water from unsaturated tuff using triaxial compression (Yang, et al. 1988) but this method is not designed to investigate unsaturated flow. To address these problems, an unsaturated fiow apparatus (UFA ${ }^{\mathrm{TM}}$ ) 
based on open centrifugation was developed in which hydraulic steady-state is achieved rapidly in most geologic media at low water contents (Conca and Wright, 1992; Conca and Wright, 1990).

\section{WATER CONTENT AND CENTRIFUGATION}

The application of a centripetal acceleration (or its inertial effect, the centrifugal force) to geologic problems is as old as centrifugation itself (Russell and Richards, 1938). However, the use of steady-state centrifugation to fix the water content and to measure unsaturated hydraulic conductivities has only recently been demonstrated by Nimmo and co-workers (Nimmo et al.,1987; Nimmo and Mello, 1991). There are specific advantages to using a centripetal acceleration as a fluid driving force. It is a body force similar to gravity, and so acts simultaneously over the entire system and independently of other driving forces, e.g., gravity or matric suction. The UFA developed for this study consists of a rock core ultracentrifuge with an ultralow constant-rate flow pump which provides any fluid to the sample surface through a rotating seal assembly and microdispersal system (Figure 1). Accelerations up to $20,000 \mathrm{~g}$ are attainable at temperatures from $0^{\circ}$ to $150^{\circ} \mathrm{C}$ and flow rates as low as $0.001 \mathrm{ml} / \mathrm{hr}$. The effluent is collected in a transparent, volumetrically calibrated container at the bottom of the sample assembly which can be observed during centrifugation using a strobe light. The maximum sample volume is 40 $\mathrm{cm}^{3}$ for aggregate materials (soils, gravels, etc. in a polyethersulfone or fiberglass sample holder) and up to $45 \mathrm{~cm}^{3}$ for solid cores (whole rock, grout, ceramic, etc., potted in casting resin and machined to the correct dimensions). The next generation UFA has, among other modifications, a maximum sample volume of $125 \mathrm{~cm}^{3}$.

Under a centripetal acceleration in which the water is driven by both the matric potential and the centrifugal force per unit volume, $\rho \omega^{2} r$, Darcy's Law is given by

$$
q=-K(\psi)\left|d \psi / d r-\rho \omega^{2} r\right|
$$

where $q$ is the flux density into the sample; $K$ is the hydraulic conductivity, which is a function of the matric suction $(\psi)$ and therefore of water content $(\theta) ; r$ is the radius from the axis of rotation; $\rho$ is the fluid density; and $\omega$ is the rotation speed. Moisture distributions in homogeneous samples run in the UFA are uniform to within 3\% (Conca and Wright, 199); Nimmo et al. 1987). Appropriate values of rotation speed and flow rate into the sample are chosen to obtain desired values of flux density, water content, and hydraulic conductivity 
in the sample. At speeds above about $300 \mathrm{rpm}$, provided that sufficient flux density exists, $d \psi / d r$ « $\rho \omega^{2} r$ and equation la reduces to $q=K(\psi)\left|\rho \omega^{2} r\right|$ or

$$
K(\psi)=q / \rho \omega^{2} r
$$

As an example, a whole rock core of Topopah Spring Member tuff accelerated to $7500 \mathrm{rpm}$ with a flow rate into the core of $2 \mathrm{ml} / \mathrm{hr}$ achieved hydraulic steady-state in 30 hours with a hydraulic conductivity of $8.28 \times 10^{-9} \mathrm{~cm} / \mathrm{sec}$ at a volumetric water content of $7.0 \%$. Previous studies have verified equation $1 \mathrm{~b}$ regarding the linear dependence of $K$ on flux and the second order dependence on rotation speed (Nimmo and Akstin, 1988; Conca and Wright, 1990)).

There are several issues surrounding flow in an acceleration field that are frequently raised and that have been successfully addressed by previous and on-going research. These include uniformity of moisture distribution, deviation of the driving force with position in the sample due to deviations in the curvatures of air-water interfaces, and com-

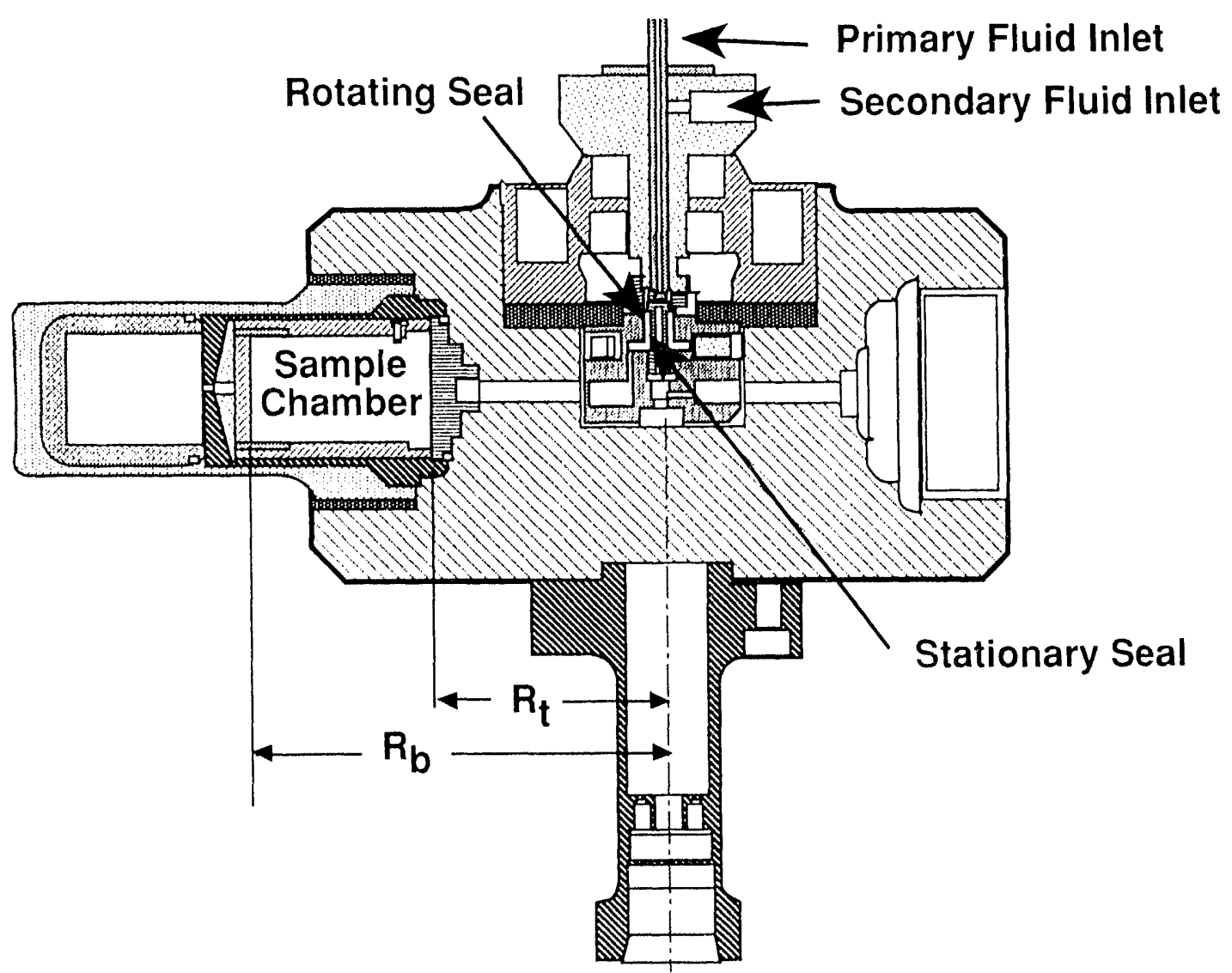

Figure 1. The UFA Rotor and Seal Assembly 
paction due to acceleration (Nimmo and Mello, 1991; Nimmo and Akstin, 1988; Nimmo et al. 1987; Conca and Wright, 1990). These studies have shown that: 1) compaction due to acceleration is negligible in samples over $1.0 \mathrm{~g} / \mathrm{cm}^{3}$ (bulk densities iil all samples have remained constant because a whole-body acceleration does not produce high point pressures); 2) three dimensional deviations of the driving force with position in the sample is less than $1 \%$, and 3 ) moisture distribution is uniform to within $3 \%$ in homogeneous systems. In heterogeneous samples or multicomponent systems, each component reaches its own hydraulic conductivity and water content at steady-state, as occurs in the field. This last effect cannot be reproduced with pressure-driven techniques, but only under a whole-body acceleration field such as gravity or centrifugal methods.

Also, the lower boundary condition of the sample and the relationship of $d \psi / d r$ to $\rho \omega^{2} r$ needs to be mentioned. The condition $d \psi / d r=0$ in the UFA only occurs after the sample has reached hydraulic steady-state. But even before steady-state occurs, as during initial infiltration into a dry sample, $d \psi / d r$ « $\rho \omega^{2} r$ for all speeds above about 300 $\mathrm{rpm}$, and this includes the lower boundary. Unlike the gravity drain situation, there is no moisture buildup at the air-water interface under a centripetal acceleration because $d \psi / d r$ « $\rho \omega^{2} r$ at all points within the system. The lower boundary of aggregate samples, such as soil, is a filter paper between the sample bottom and a perforated plastic plate. Additionally, the boundary condition issue of flow down the sample container interior sides, circumventing the sample and affecting $K(\theta)$, has not been observed to occur in the UFA. Flow down the sample container exterior sides is prevented by O-ring seals.

\section{COMPARISONS TO TRADITIONAL TECHNIQUES}

Hydraulic conductivities of unsaturated sediments from the Buried Waste Test Facility (BWTF) at the Hanford Site were determined over the water content range from $5 \%$ to $40 \%$ using the UFA method and three traditional techniques (Figure 2). These sediments are coarse to medium grained fluvio-glacial soils of a dominantly volcanic source lithology, having approximately $85-90 \%$ sand, $5-10 \%$ silt and 3-6\% clay by weight for the $<2 \mathrm{~mm}$ size fraction. Open squares are direct measurements of $K(\theta)$ obtained in a three-day period using the UFA. Open triangles are direct measurements of $K(\theta)$ using traditional column flow experiments under unit-gradient conditions, requiring about a year of experimental time to achieve the hydraulic steady-states over this water content range (Mike Fayer, personal communication). A Campbell relationship was fit to water retention data for the BWTF soil and used to generate a Mualem relationship (the solid curve). Also shown in Figure 2 is 13-year field lysimeter data obtained under unit-gradient conditions at water 


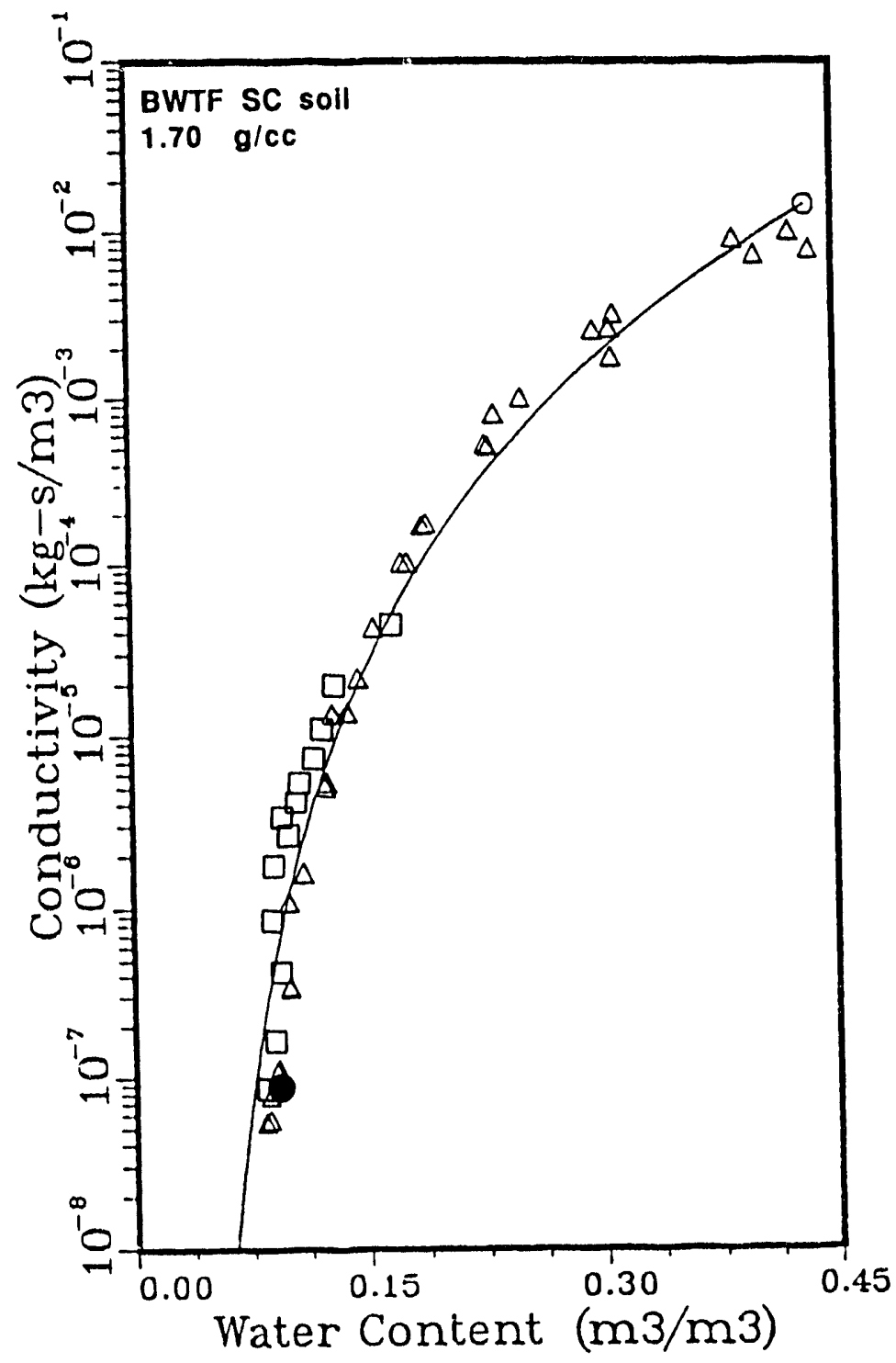

$\square$ UFA $^{\mathrm{TM}}$ measurements made over 3 -days

$\triangle$ Traditional column experiments made over 1-year

- Average of rield lysimeter measurements made over 13-years

- Mualem estimation derived from curve-fitted water-retention data made over 6-weeks

Eigure 2. Characteristic Curves for the BWTF Soil Obtained Using Four Different Methods. 
contents in the field (Glendon Gee, personal communication), a point which ties the laboratory data to the field conditions. The agreement of the UFA data with all three methods is excellent and demonstrates the feasibility and rapidity of the UFA method.

It was anticipated that different techniques would compare well for the BWTF soils because the traditional techniques were originally developed for sands and sandy loams. However, these techniques have never been validated for silts, clays, rocks or other less permeable media. Therefore, a comparison was run among the UFA method and two traditional methods on a fine silt from the Field Lysimeter Test Facility (FLTF) at the Hanford Site that achieves hydraulic conductivities in the low water content range similar to some of the Yucca Mountain tuffs. The results are shown in Figure 3. Circles are data from falling head permeameter studies, and triangles and squares are laboratory data from steady-state soil column studies (Glendon Gee, personal communication). The solid line is the Mualem relationship generated from a van Genuchten relationship fit to water retention data for the FLTF soil (fitting parameters are listed on the figure). The agreement among these methods is still very good. At low water contents, the estimate overpredicts the hydraulic conductivity relative to the UFA, or conversely, the estimate underpredicts the residual saturation. Considering that these tests for the BWTF and the FLTF soils were performed blind, the agreement is better than expected.

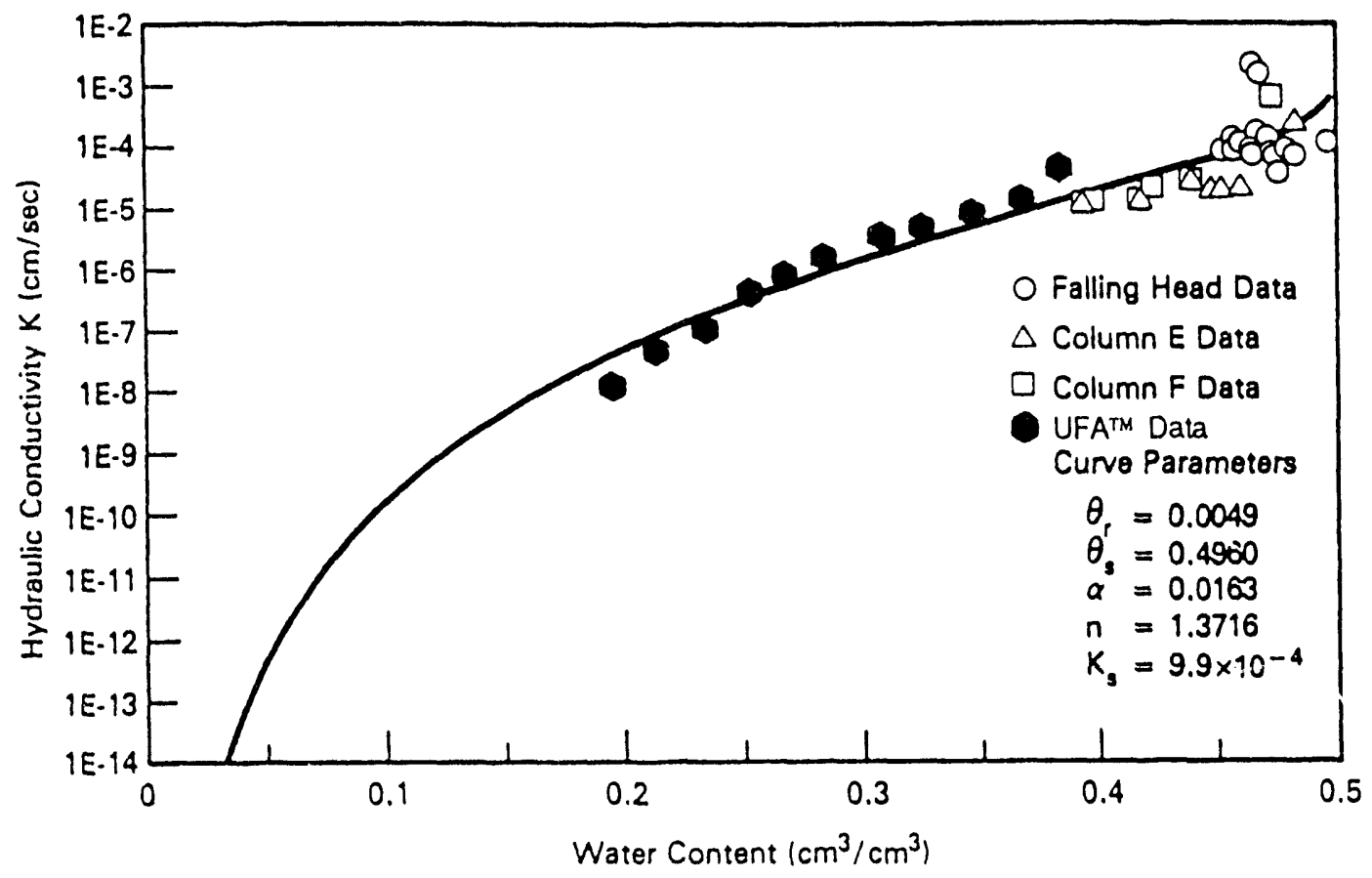

Figure 3. Measured Hydraulic Conductivity Data and van Genuchten Function Fit for FLTF Soil using Three Different Methods. 


\section{PREVIOUS STUDIES ON REPOSITORY ROCKS}

Whole rock cores of Topopah Spring Member and Calico Hills tuff were run in the UFA to generate characteristic hydraulic conductivity relationships for each rock and to investigate the tuff whole rock systems in light of current capillary bundle theory which predicts the desaturation of progressively smaller aperture fractures with decreasing water content. The water distribution in a whole rock core of tuff with a natural single large $200 \mu \mathrm{m}$ fracture that almost, but not completely, spans the core is shown in Figure 4 . The approximate volumetric water content is $\theta \sim 7.0 \%$ ( $88 \%$ of saturation) in the wetted rock after two hours at $7500 \mathrm{rfm}$ with a flow rate into the core of $2 \mathrm{ml} / \mathrm{hr}$. Water has infiltrated the matrix but the fracture has not begun conducting any water. $K$ is the unsaturated hydraulic conductivity at the approximate volumetric water content of $7 \%$.

Figure 5 shows the water distribution in the same whole rock core as Figure 4 after the flow rate was increased to $5 \mathrm{ml} / \mathrm{hr}$. The fracture catastrophically drained $6 \mathrm{ml}$ over a ten minute period after one hour under these conditions. $K$ is the hydraulic conductivity of the saturated system, matrix plus fracture, at a volumetric water content of approximately $7.9 \%$. The top portion of the wetted matrix and the fracture walls to a depth of less than $1 \mathrm{~mm}$ were saturated. This indicates that while the matric potential at high accelerations does not significantly contribute to the driving force in the Darcy relationship, the matric potential does influence the moisture distribution and flow paths analogously to the $1 \mathrm{~g}$ situation as predicted by capillary bundle theory. The matrix immediately adjacent to the fracture must be saturated before the fracture will conduct water.

Characterization of the flow paths within the tuff can also be accomplished using a dyed groundwater (India ink in water has been successful for these thin section analyses) as the infusing liquid. An example is illustrated in Figure 6 which shows a photomicrograph of a thin section through a core perpendicular to the flow direction illustrating fluid flow through the fractured matrix and along cleavage fractures in a large feldspar grain (Conca and Wright, 199()). Areas of blue indicate the flow paths. Notice the dendritic pattern of a lateral flow path in the feldspar. These "dead end" flow paths do not contribute significantly to the hydraulic conductivity but greatly influence the aqueous chemistry because of long fluid residence times. Once the core sample is infused with dye, thin sections can be mapped using image analysis to produce a 3-dimensional image of the flow porosity. When the resolution of other imaging techniques, such as CT and CIT, reaches 


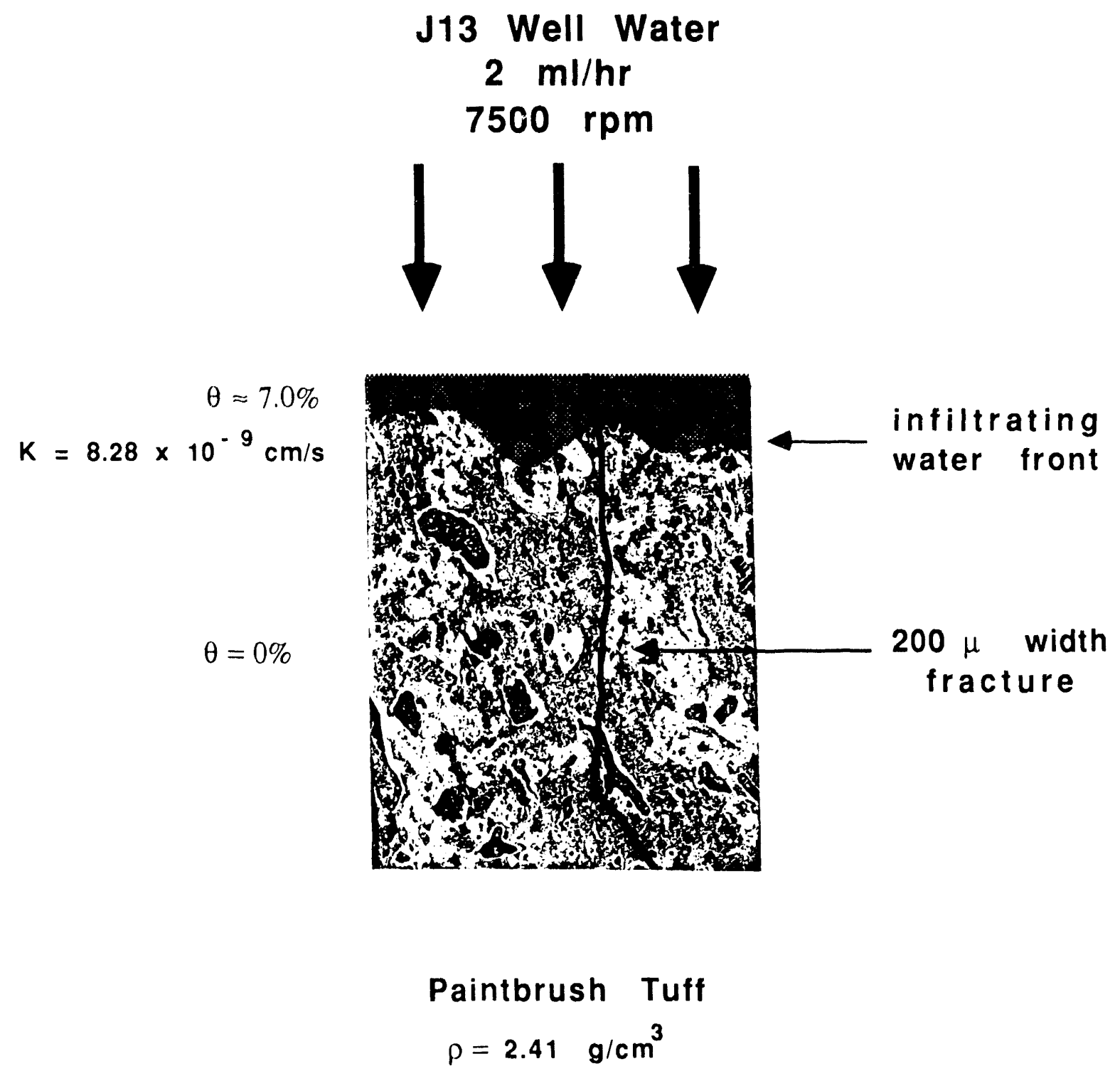

Figure 4. Water Distribution in a Whole Rock Core of Tuff with a Single Natural Large Fracture that Almost but not Completely Spans the Core. After Two Hours at $7500 \mathrm{rpm}$ Rotation Speed and $2 \mathrm{ml} / \mathrm{hr}$ Flow Rate, Water has Infiltrated the Matrix but not the Fracture. 


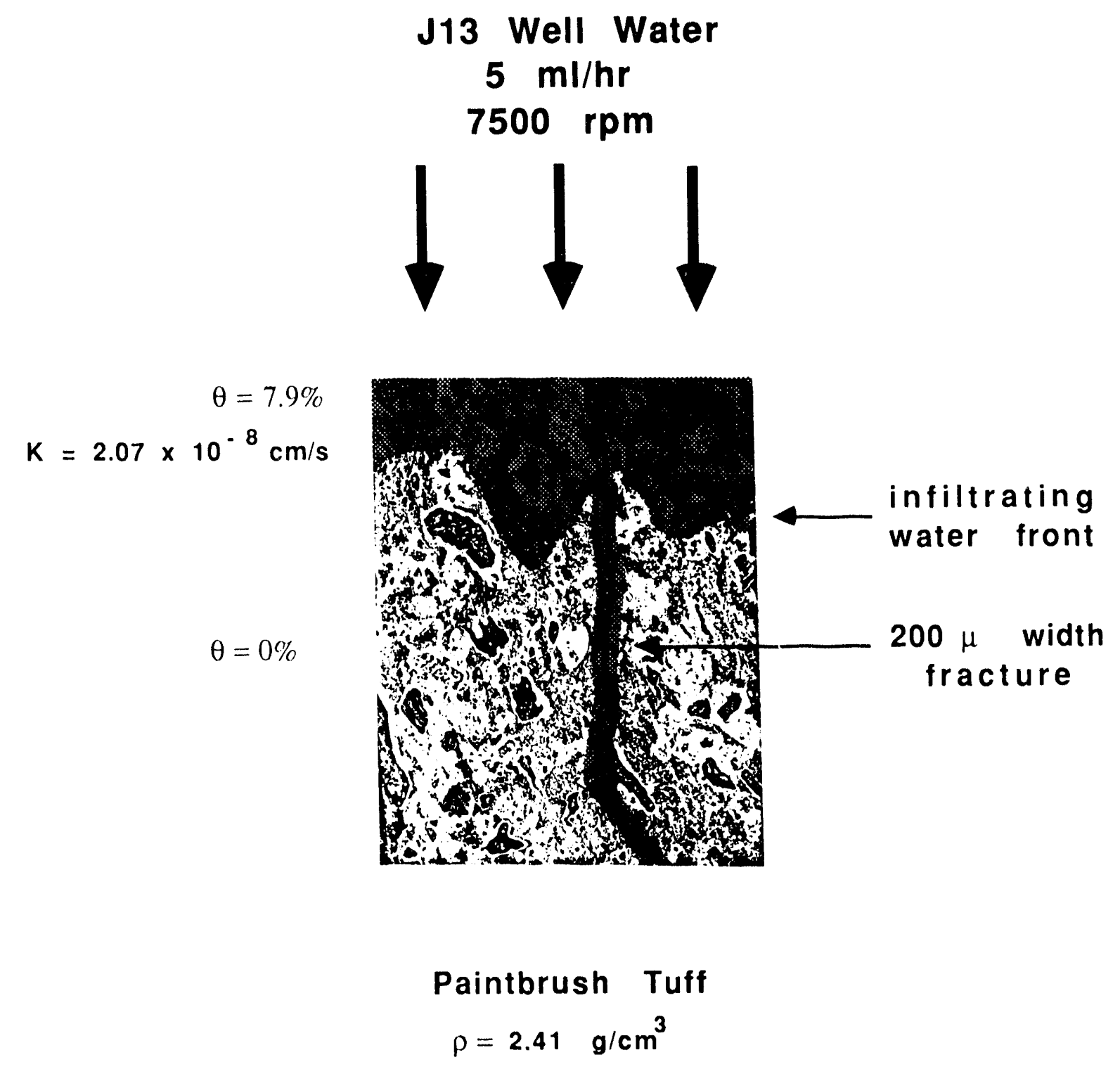

Figure 5. Water Distribution in the Same Core as in Figure 4 One Hour After Flow Rate Increased to $5 \mathrm{ml} / \mathrm{hr}$. The Fracture Drained $6 \mathrm{ml}$ over a Ten Minute Period After the Matrix Began Saturating. 

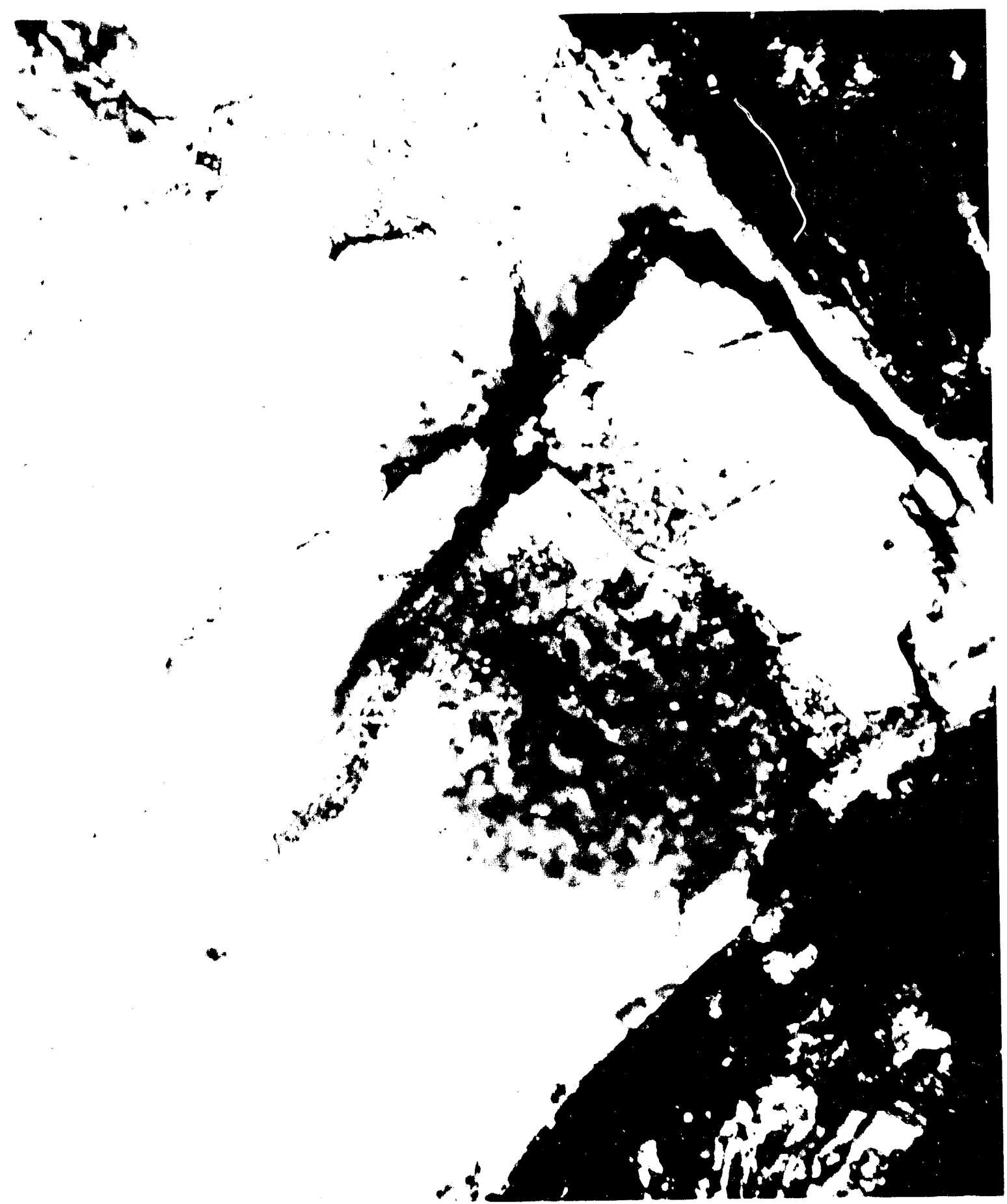

Eigure 6. Photomicrograph of a Thin Section Through a Core of Tiva Canyon Member Tuff Perpendicular (o) Flow lllustrating Fluid Flow along Cleavage fractures in a Large Feldspar Grain. Areas of Blue Indicate the Flow Paths, which were Sparse and lnevenly Distributed in Both the Tuff Matrix and in the Phenocrysts. Field of View is $2 \mathrm{~mm}$. Iarge Fractures have Apertures between 50 and $100 \mu \mathrm{m}$, While Smaller Fractur ss have Apertures less than $10 \mu \mathrm{m}$. 
the micron level, then the UFA will be used in conjunction with them to non-destructively map water distribution as a function of water content within the same core.

Figure 7 and Table 1 show some results of UFA studies with the Power Reactor and Nuclear Fuel Development Corporation (PNC) for Japan's high-level nuclear waste geologic repository program. The thrust of this study was to completely characterize the near-field transport characteristics using the UFA in conjunction with other techniques (see section below on Aqueous Diffusion). Figure 7 includes the four candidate host rock types investigated and the compacted bentonite barrier material. The proposed repository occurs below the water table, so it is assumed that the materials will be saturated after the initial desiccation phase has passed. Italicized values are those that were measured in the UFA except for $R_{f A m}$ in the bentonite which was measured by Ashida and co-workers at PNC using half-cell diffusion methods (Ashida et al., 1993). The PNC tuff is a very porous, homogeneous, but relatively impermeable, rock that has less lithic fragments and glass shards than the Yucca Mountain tuffs and is less fractured.

\section{Table 1. Transport Parameters in PNC Japan's Repository Host Rocks Using the UFA}

\begin{tabular}{|c|c|c|c|}
\hline Rock Type & & $\mathrm{K}(\mathrm{cm} / \mathrm{s})$ & D) $\left(\mathrm{cm}^{2} / \mathrm{s}\right)$ \\
\hline basalt & 1 (fractured) & $2.98 \times 10^{-9}$ & $2.52 \times 10^{-8}$ \\
\hline basalt & 2 & $2.13 \times 10^{-10}$ & $4.56 \times 10^{-9}$ \\
\hline basalt & 3 (fractured) & $4.03 \times 10^{-9}$ & $1.46 \times 10^{-8}$ \\
\hline basalt & 4 & $<7.1 \times 10^{-12}$ & $1.90 \times 10^{-8}$ \\
\hline granite & 1 & $1.90 \times 10^{-9}$ & $7.73 \times 10^{-9}$ \\
\hline granite & 2 & $2.95 \times 10^{-9}$ & $1.13 \times 10^{-8}$ \\
\hline granite & 3 & $1.34 \times 10^{-9}$ & $8.30 \times 10^{-9}$ \\
\hline granite & 4 & $2.49 \times 10^{-9}$ & $1.77 \times 10^{-8}$ \\
\hline mudstone & 1 & $1.45 \times 10^{-10}$ & $4.31 \times 10^{-9}$ \\
\hline mudstone & 2 & $1.34 \times 10^{-10}$ & $4.23 \times 10^{-9}$ \\
\hline muai.rone & 3 & $1.84 \times 10^{-10}$ & $5.54 \times 10^{-9}$ \\
\hline mudstone & 4 & $1.40 \times 10^{-10}$ & -- \\
\hline tuff & 1 &.- & $7.48 \times 10^{-6}$ \\
\hline tuff & 2 & $2.21 \times 10^{-7}$ & $6.17 \times 10^{-6}$ \\
\hline tuff & 3 & $8.82 \times 10^{-8}$ & $5.77 \times 1()^{-6}$ \\
\hline
\end{tabular}




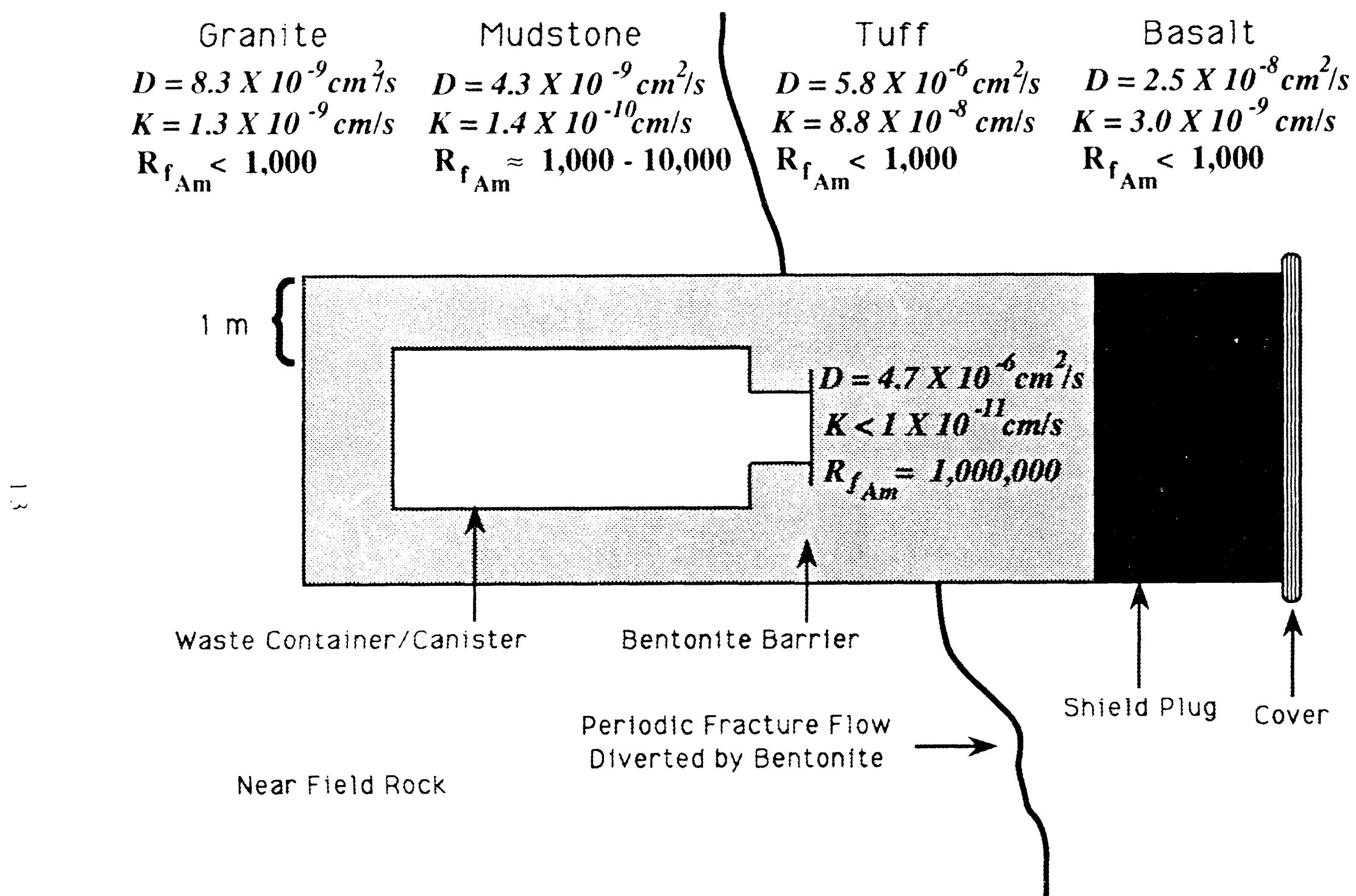

Figure 7. Transport Parameters Measured in the Bentonite and Each Candidate Host Rock. Rf Values in the Host Rocks are Estimated from the Literature and/or Extrapolated from Cs Behavior. 
Table 1 lists the hydraulic conductivity and diffusion coefficients determined for the PNC candidate host rocks using the UFA over a three-week period. Flow effects from fractures or bedding structures can be investigated by running different samples of the same rock type exhibiting different features. As expected, fractures in the basalt strongly effected advection but not diffusion whereas bedding structures in the mudstone had no effect on either advection or diffusion.

\section{RESULTS}

The unsaturated hydraulic conductivities for several tuff units from Yucca Mountain investigated using the prototype UFA are shown in Figure 8. There are few data because the new generation UFA, which can achieve lower $K$ and $\theta$, has only recently been completed. The $K(\theta)$ relationship appears to be steep for each sample when plotted as a function of volumetric water content because the pore size distribution affected over this water content range is very narrow. However, $K(\theta)$ falls in distinct fields for the welded, vitric and zeolitized tuffs indicating that each rock type is controlled by a distinctly different pore size distribution. Figure 9 plots a hysteretic curve for the vitric member that ran for 191.6 hours. Hydraulic steady-state was achieved at each point, and the run began from the saturated state. Because hysteresis is important in relation to the water potential but negligible with respect to hydraulic conductivity, hysteresis is not noticeable when the UFA is used to determine the characteristic behavior because the UFA directly measures $K(\theta)$ and not $\psi(\theta)$.

Hydraulic steady-state really applies only to the flow porosity, and not to the diffusion porosity which is unconnected to the overall flow porosity (Norton and Knapp, 1977). Therefore, one can achieve hydraulic steady-state with respect to the flow porosity and not have reached the steady-state water content with respect to the diffusion porosity. Under normal unit-gradient subsurface conditions, this will not be important, as the diffusion porosity will always be saturated, and changes in water content occur primarily in the flow porosity as expected by capillary bundle theory. However, in the near-field of the repository during re-invasion by the ground water, or in the event of a leak, the diffusion porosity may experience changes in saturation between fully dry and fully saturated. Figure 10 shows two curves for the vitric member. The crosses indicate the situation in which hydraulic steady-state was achieved with respect to the flow porosity and with the diffusion porosity saturated, i.e., the tuff was begun saturated. The closed circles indicate the situation in which hydraulic steady-state was achieved with respect to the flow porosity but the diffusion porosity was not saturated, i.e., the tuff began dry and the experiment 


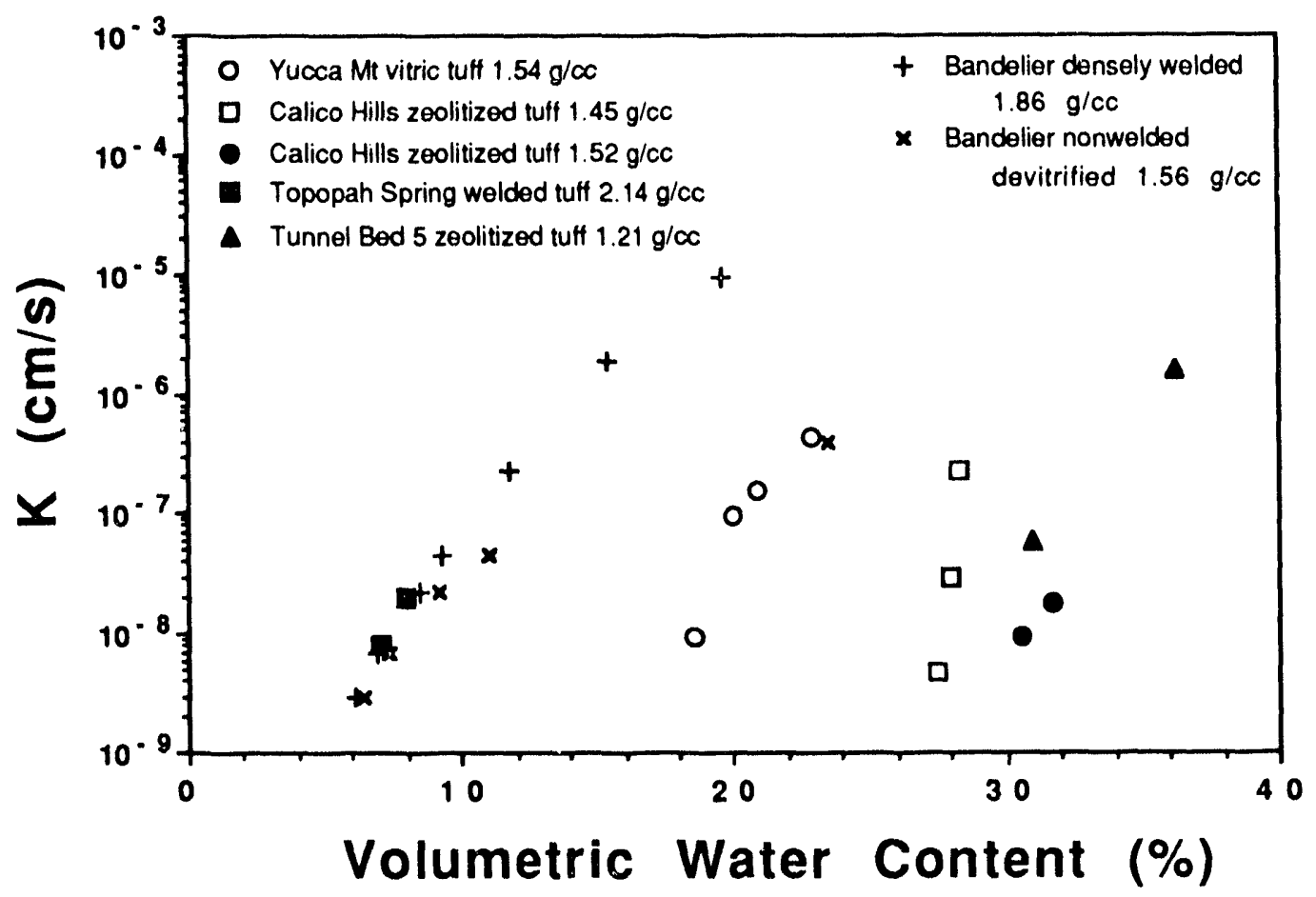

Floure 8. Unsaturated Hydraulic Conductivities for Various Tuffs.

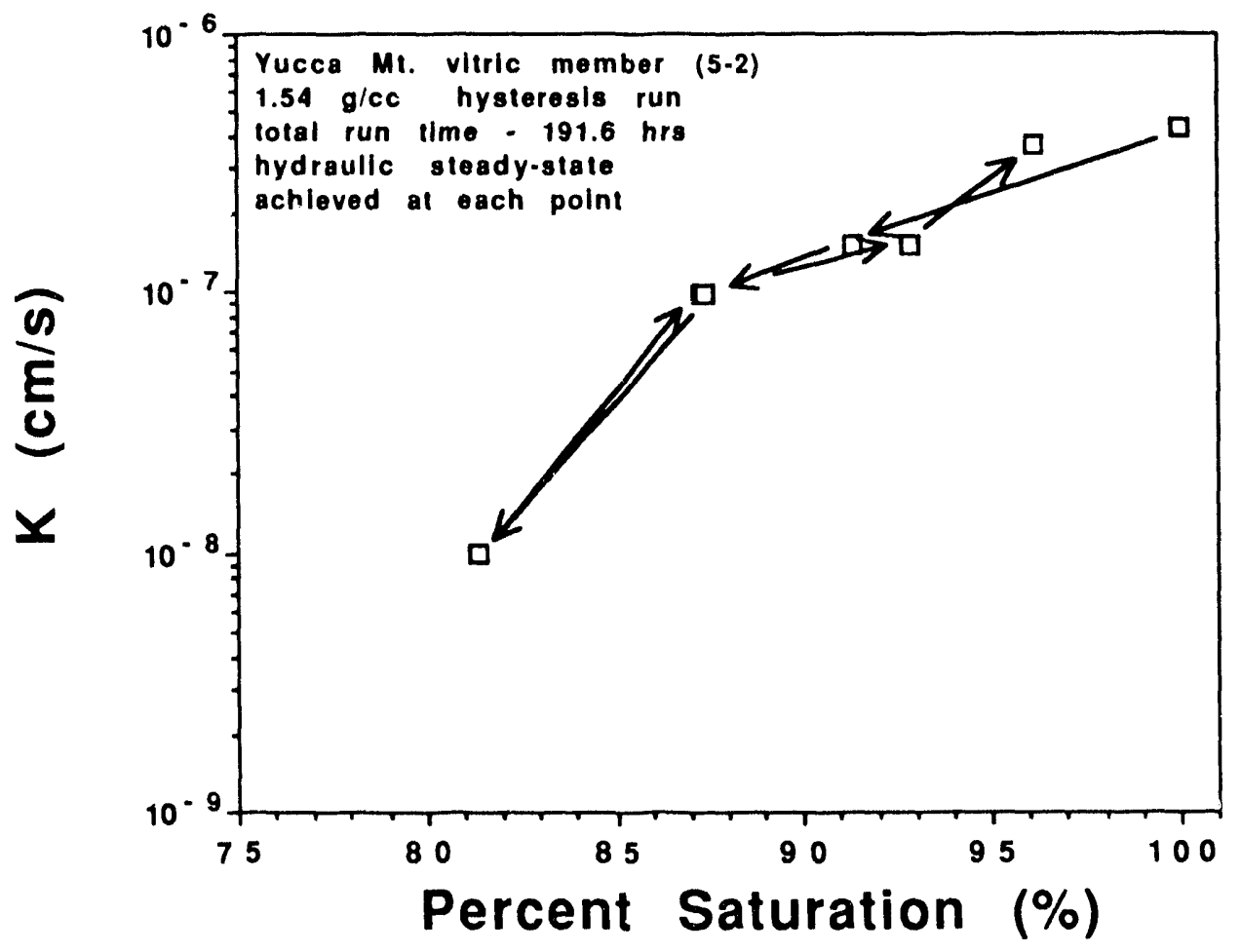

Elqure 9. Hysteresis In the Yucca Mt. Vitrlc Member. 


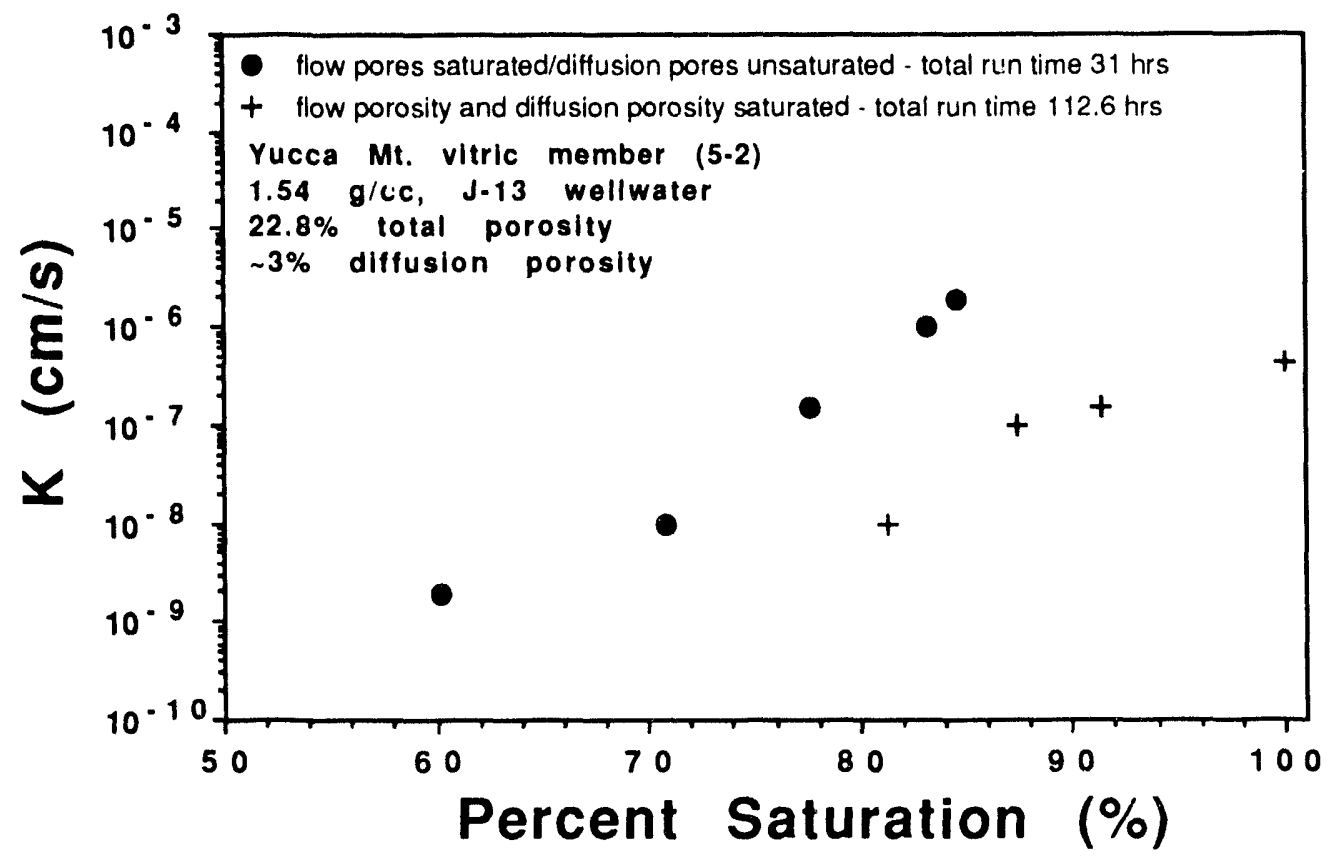

Flgure 10. Hydraullc Steady-State Achleved with Respect to the Flow Porosity with and without Saturating the Diffusion Pores

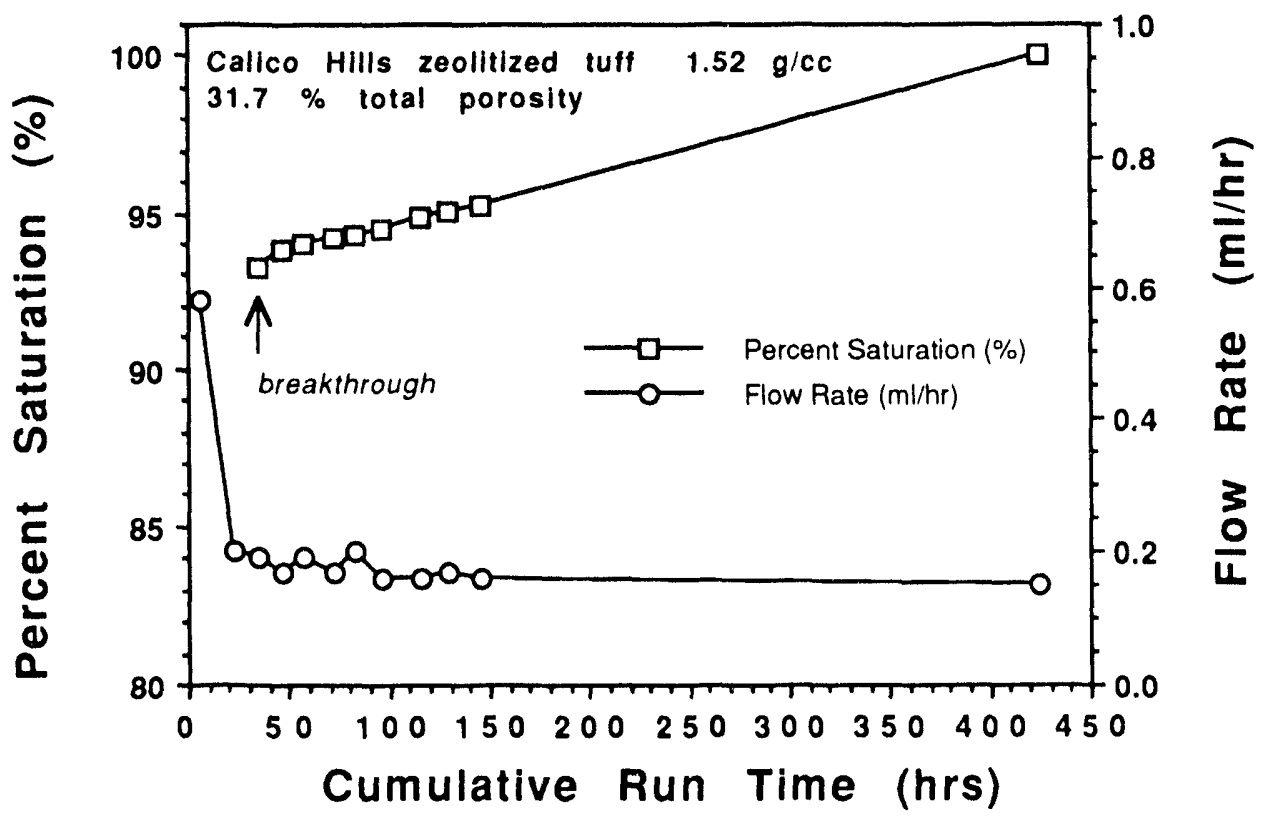

Elqure 11. Time Required to Saturate the Diffusion Porosity in the Calico Hills Zeololtized Tuff After the Flow Porosity has Achleved Hydraullc Steady-State. 
was fast enough that the diffusion porosity did not appreciably saturate, although the diffusion of water into the diffusion pores was constantly taking place. The difference between the two curves indicates a diffusion porosity of about $3 \%$ by volume out of a total pore volume of $22.8 \%$, a small but significant volume that is not hydraulically connected to migrating waters but is chemically connected through diffusion.

Figure 11 illustrates this difference for a sample of the zeolitized Calico Hills tuff with a total porosity of $31.7 \%$. The run was started with the core oven-dried at $60^{\circ} \mathrm{C}$. This drying was necessary to ensure proper adhesion of the epoxy sample jacket and the effect of drying on the sample properties is considered mininial as repeated cycles did not cause noticeable changes in physical properties or hydraulic conductivity. The initial gravity-fed flow rate was $0.6 \mathrm{ml} / \mathrm{hr}$, a rate which saturated the top of the sample. This rate was the result of the hydraulic conductivity of the sample and the large matric potential occurring during imbibition into dry tuff. This flow rate declined over the next 20 hours as the connected fractures and matrix became saturated to level off at $0.16 \mathrm{ml} / \mathrm{hr}$. At iust under 40 hours, breakthrough occurred from the end of the sample. Because the flow rate did not change appreciably over the remaining duration of the run, the flow porosity was evidently saturated prior to or just after breakthrough, and the water content at that point is indicative of the volume of the flow porosity minus whatever diffusion porosity had become saturated. However, the water content continued to slowly increase over the next 380 hours as the diffusion porosity saturated. This data provides some relative rates of migration within this material during advective flow and during diffusion, of both water and dissolved species.

From the dry state, this sample of the zeolitized Calico Hills tuff took about 425 hours to reach its saturated steady-state water content. After that occurred, the sample was then forced to reach a slightly unsaturated hydraulic steady-state at $96 \%$ of saturation (Figure 12). This required significantly less time, only about 50 hours. It is, therefore, more time-efficient to run these samples from the saturated state, and more relevant to the field conditions.

Figure 13 shows the hydraulic conductivity of the Yucca Mountain vitric member and the Topopah Spring welded tuff along with several different geologic materials, putting the tuff $K(\theta)$ into perspective with other porous media. The two soils bracket most soil behavior, especially arid soils at the Yucca Mountain Site. The gravel made of crushed Topopah Spring tuff exhibits the extreme drainage behavior of gravels in general. The open circles are measured saturated and near-saturated hydraulic conductivities for the rock 


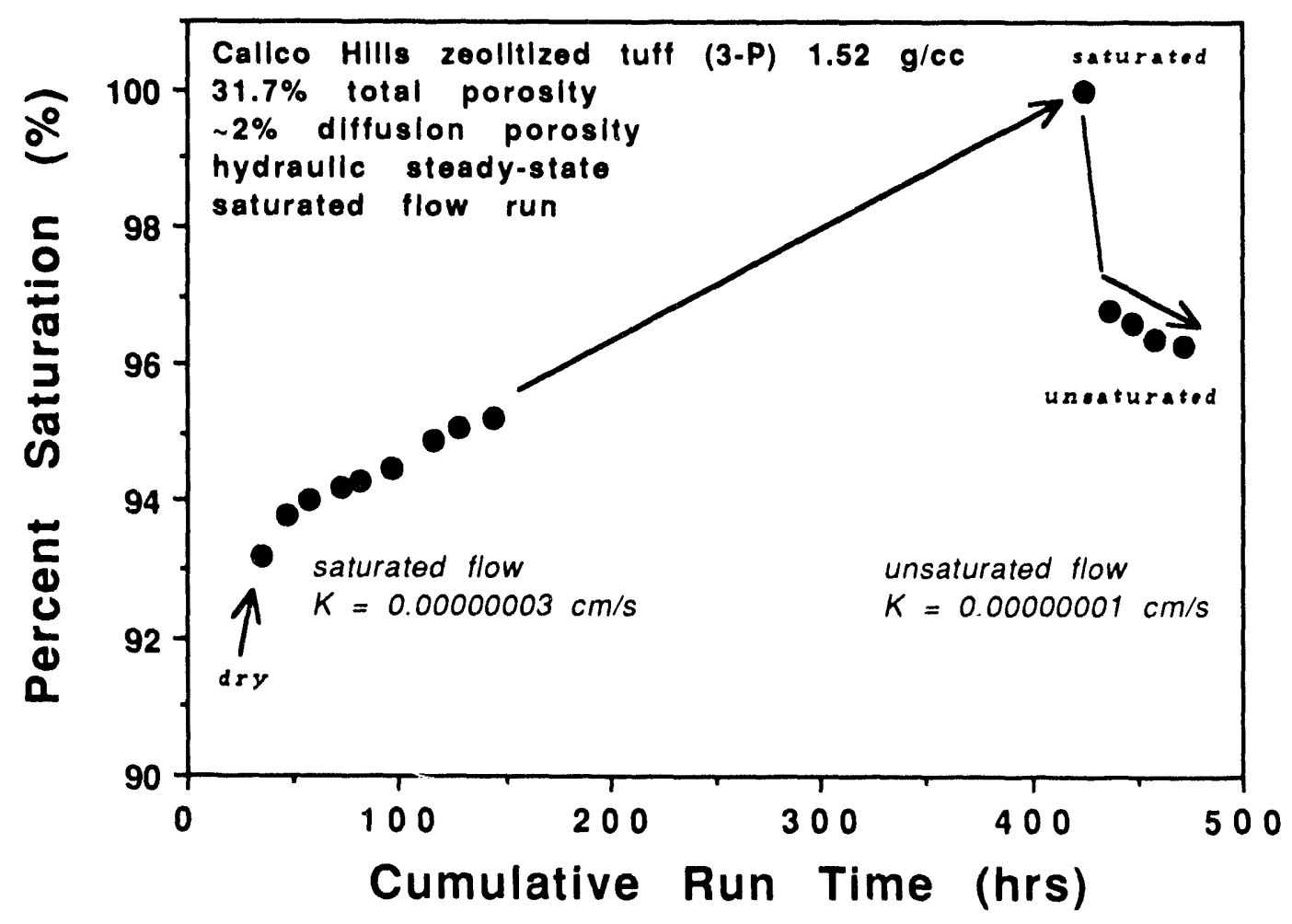

Figure 12. Time Required to Achieve Hydraulic Steady-State from the Dry State Compared to the Saturated State.

core of Topopah Spring welded tuff with the single $200 \mu \mathrm{m}$ aperture fracture previously mentioned. The circle with the horizontal slash is the measured hydraulic conductivity of that fracture normalized to a fracture abundance of one fracture per square centimeter of tuff $\left(2 \times 10^{-7} \mathrm{~cm} \mathrm{~s}^{-1}\right)$. The circle with the diagonal slash is the calculated saturated hydraulic conductivity of an impermeable-matrix fractured rock with $200 \mu \mathrm{m}$ aperture fractures and a fracture abundance of one fracture per centimeter of rock using the idealized fracture flow relationship from Norton and Knapp (1977):

$$
k=n d^{3} / 12
$$

where $k$ is the intrinsic permeability $\left(\mathrm{cm}^{2}\right), n$ is fracture abundance $\left(\mathrm{cm}^{-1}\right)$ and $d$ is the fracture aperture $(\mathrm{cm})$. The hydraulic conductivity, $K$, is related to the intrinsic permeabili- 
ty through the fluidity relationship:

$$
K=k \rho g / \eta
$$

where $\rho$ is the fluid density, $g$ is the gravitational acceleration, and $\eta$ is the fluid viscosity. For water flowing through a rock with $200 \mathrm{~mm}$ aperture fractures with one fracture per centimeter, $n=1 \mathrm{~cm}^{-1}, d=0.02 \mathrm{~cm}, \rho=1 \mathrm{~g} \mathrm{~cm}^{-3}, \eta=0.01$ poise (combined units of $\mathrm{g} \mathrm{s}^{-1}$ ), and $g=980 \mathrm{~cm} \mathrm{~s}^{-2}$, giving $K=0.059 \mathrm{~cm} \mathrm{~s}^{-1}$. The calculated value is higher than

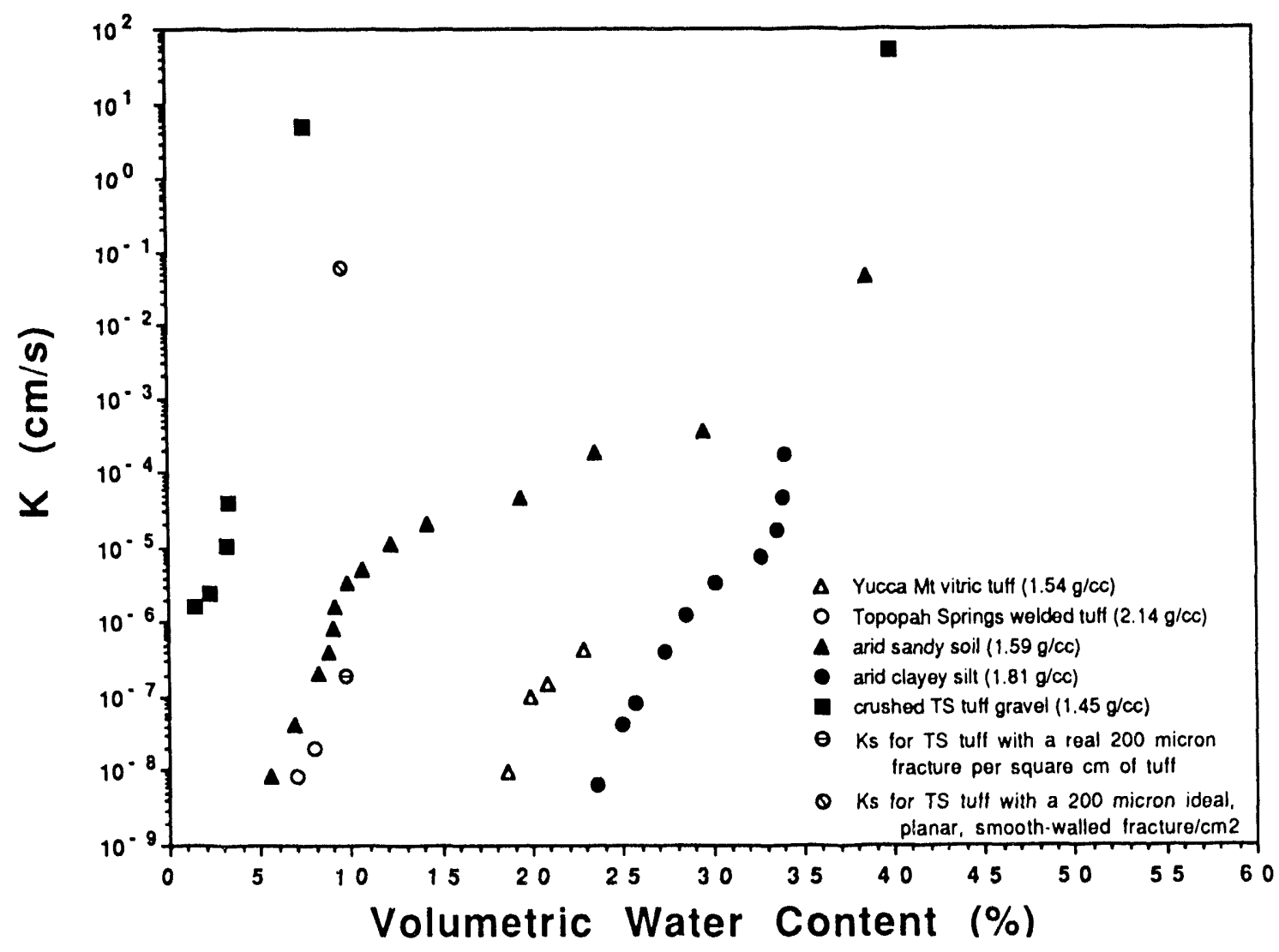

Figure 13. Hydraulic Conductivity as a Function of Volumetric Water Content for Two Yucca Mountain Tuffs Compared to Other Geologic Materials and a Theoretical Calculation. 
the measured value of $2 \times 10^{-7} \mathrm{~cm} \mathrm{~s}^{-1}$ for the $200 \mu \mathrm{m}$ aperture fracture normalized to a fracture abundance of one fracture per centimeter because the actual fracture is not planar, smooth-walled or of constant aperture size throughout the rock. The $200 \mu \mathrm{m}$ aperture was measured where the fracture intersected the sample surface, and may not represent the aperture size in the sample interior. The difference between the two hydraulic conductivity values is a factor of $2.95 \times 10^{5}$ and illustrates the difficulty of idealizing fracture characteristics from sparse measurements. Also, the above fluidity relationship was developed for saturated conditions only, and is not applicable to unsaturated conditions because matric potential is as important as the fluid viscosity and density in determining hydraulic conductivity. Additionally, matric potential is a strong function of fracture and matrix aperture sizes.

\section{AQUEOUS DIFFUSION}

Diffusion coefficients have been determined in a variety of materials using various methods. However, unsaturated conditions present unique experimental problems. Diffusive fluxes through unsaturated materials require longer time periods to collect sufficient data from transient-state experiments. Maintaining proper boundary conditions for direct steady-state techniques under unsaturated conditions is extremely difficult and has yet to be satisfactorily demonstrated. Recently, an indirect method was developed that measures electrical conductivity in a potentiostatic or galvanostatic mode coupled with the Nernst-Einstein relationship, which provides reliable estimates of diffusion coefficients (Miller, 1972). A variation of the two-electrode method was found to be ideal for studies of geologic media. Electrical conductivity is related to the migration of ions in an aqueous solution because the ease with which ions can migrate through an aqueous solution is exactly analogous to the ease with which the aqueous species can align their dipoles along the electric field vector, as long as the frequency is appropriate. Conductivity measurements of aqueous solutions actually measure the impedance (the AC analog of DC resistance) at the impressed frequency which is a complex variable vector sum of the real in-phase (resistive) and the imaginary out-of-phase (reactive) components of the system response. For conductivity measurements (conductivity is the reciprocal of resistivity) using AC excitation, it is the in-phase component of impedance that is a measure of the true solution resistivity (or conductivity) and that can be used to represent the migration of ions in solution in geologic materials. Therefore, the impedance must be totally resistive, i.e., no capacitive elements, for the Nernst-Einstein relationship to be applicable. This was 
verified for saturated and unsaturated geologic systems with a $1 \mathrm{kHz}$ bridge using electrochemical impedance spectroscopy which gives direct information about the real and imaginary components of impedance as a function of excitation frequency (Conca and Wright, 1990). The impedance in these systems is a constant, frequency-independent quantity in the 600$)$ to 7,000$) \mathrm{Hz}$ region, and is totally resistive in the 400 to $10,000 \mathrm{~Hz}$ region. Thus, the measured impedance at $1 \mathrm{kHz}$ on unsaturated geologic systems is a good measure of the true system resistance and its reciprocal, conductivity, and will give reliable values for diffusion coefficients calculated from the Nernst-Einstein equation. In addition, we have determined $D(\theta)$ on the same soils using the UFA-electrical conductivity method and using Kemper's empirically-derived relationship (Bresler et al., 1982) and the agreement is excellent $\left(\mathrm{R}^{2}=0.99\right.$; Wright, 1990). Once electrical conductivity measurements are made, they can be related to the diffusion coefficient through the NernstEinstein equation (Conca and Wright, 1990)

$$
D_{i}=\frac{R T}{F^{2}} \times \frac{\Theta G t_{i}}{Z_{i} C_{i}}
$$

where $D_{i}$ is the diffusion coefficient of the $i t h$ ion $\left(\mathrm{cm}^{2} / \mathrm{sec}\right), R$ is the gas constant (J/deg mol), $T$ is absolute temperature (Kelvin), $F$ is Faraday's constant (coul/mol), $\Theta$ is the cell constant for the UFA conductivity cell sample holder $\left(\mathrm{cm}^{-1}\right), G$ is the measured conductance on the conductivity bridge (mhos), $t_{i}$ is the transport or transference number of the ith ion $\left(\mathrm{t}_{\mathrm{K}^{+}}=0.4898\right.$ at $\left(0.1 \mathrm{M} ; \mathrm{t}_{\mathrm{Na}^{+}}=0.3854\right.$ at $(0.1 \mathrm{M}), Z_{i}$ is the charge number on the $i$ th ion (dimensionless) and $C_{i}$ is the molar concentration of the ith ion. The diffusion coefficients determined in this study have been corrected for solution non-ideality using the extended Debye-Hückel approximation (Stumm and Morgan, 1981). Effluent is monitored to correct for possible water/substrate interactions which can change the solutiois electrolyte concentrations, although these interactions were not significant during these experiments.

Simple diffusion coefficients in aqueous solution at $25^{\circ} \mathrm{C}$ for almost all chemical species, including organics, are between $0.5 \times 10^{-5} \mathrm{~cm}^{2} / \mathrm{sec}$ and $2.1 \times 10^{-5} \mathrm{~cm}^{2} / \mathrm{sec}$ (Conca and Wright, 1992; Oelkers, 1991; Robinson and Stokes, 1959). Therefore, simple diffusion coefficients in porous media that are less than $10^{-6} \mathrm{~cm}^{2} / \mathrm{sec}$ at $25^{\circ} \mathrm{C}$ result from mechanisms or conditions other than the inherent mobility differences between the ions themselves. $D$ represents a generic simple diffusion coefficient at infinite dilution that is a bulk property of the system and refers to the various combined physical effects of the porous media. This differs from the apparent diffusion coefficient, $D_{a}$, which includes 
retardation and other transient chemical effects and is specific for each species, medium, and fluid composition. Numerical models using $D(\theta)$ as an input parameter require the simple diffusion coefficient. Once breakthrough has occurred for a particular species, retardation ceases and the diffusion coefficient attains the simple value which can be orders of magnitude higher than the apparent diffusion coefficients for many species in materials such as zeolitized tuff or bentonite. The point at which breakthrough occurs is determined by the capacity of the flow paths in the media for that species under appropriate conditions.

Figure 14 shows over 300 diffusion coefficients in a variety of geologic and engineered barrier materials. The $D(\theta)$ relationship is characterized at higher water contents by a gradual decline in $D(\theta)$ as water content decreases, followed by a steep drop-off at low water contents because of the loss of continuous water pathways as the surface films become thin and discontinuous and the pendular water elements become very small, or the saturated apertures become very small. The diffusion coefficients for all materials fall into a narrow range of distribution and demonstrate that the diffusion coefficient is dependent

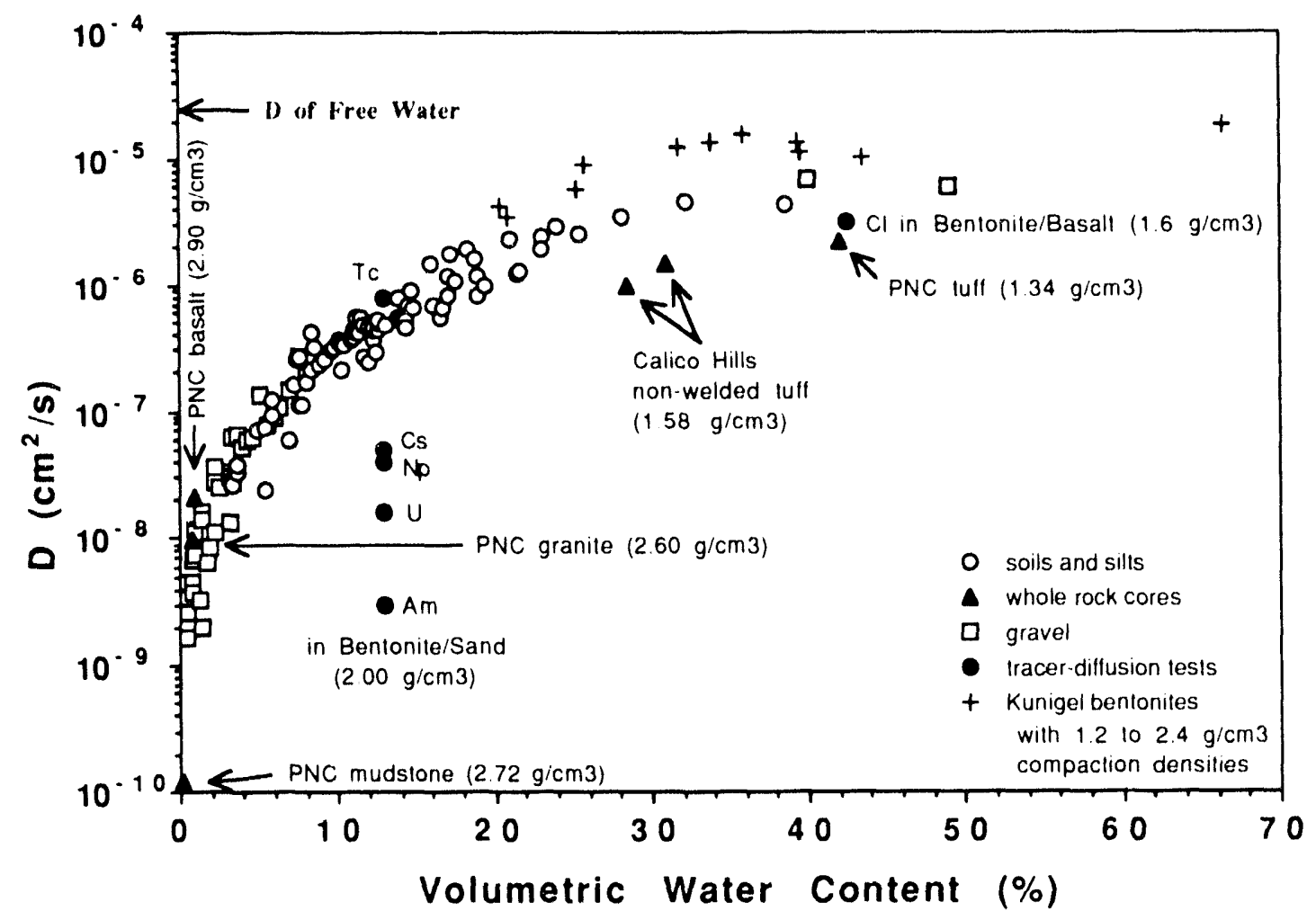

Figure 14. Diffusion Coefficients in Various Geologic Media as a Function of the Free Volumetric Water Content. 
primarily upon volumetric water content, and only secondarily on material type at any given water content. No such relationship occurs for wt\% water content or degree of saturation. Of course, the material properties determine the unsaturated volumetric water content, especially in aggregate materials such as gravels and soils which can have similar porosities (and, therefore, similar saturated diffusion coefficients) but very different water retention properties under the same hydrologic regime. Whole rock appears to behave similarly to aggregate materials, although not many data have been collected. Therefore, if different materials have the same volumetric water content, then their diffusion coefficients wil! be the same, within a factor of about two. As an example, a saturated fractured whole rock, with a total porosity of $10 \%$, and an unsaturated gravel, with a total porosity of $40 \%$ that is only $25 \%$ saturated, both have $\theta=10 \%$ with a corresponding $D$ of $3 \times 10^{-7} \mathrm{~cm}^{2} / \mathrm{sec}$. Fractured media can be synthesized with ideal, smooth-walled, planar fractures, or with excessive amounts of water-filled unconnected porosity, that do not follow this relationship, but natural materials have highly tortuous diffusion paths, and log-normal distributions of fracture/fracture apertures or pore volume/throat distributions that are similarly affected by surface and bulk water. Increasing the water content decreases the diffusion path lengths.

Also shown in Figure 14 as closed circles are apparent diffusion coefficients measured on compacted bentonite by half-cell methods (Albinsson and Engkvist, 1989; Relyea et al., 1986). $\mathrm{Cl}^{-}$and $\mathrm{TcO}_{4}{ }^{-}$are considered to be not retarded by bentonite and compare well with the data from the electrical conductivity method. However, once chemical equilibrium is reached in the bentonite, the apparent diffusion coefficients for $\mathrm{Cs}, \mathrm{Np}, \mathrm{U}$ and $\mathrm{Am}$ will increase to that of $\mathrm{Tc}$ and $\mathrm{Cl}$. The time required to reach equilibrium depends upon the situation and may or may not be important over regulatory time frames.

\section{RETARDATION}

Retardation factors can be determined in flow experiments where $R_{f}$ for a particular species is the ratio of the solution velocity to the species velocity. The retardation factor for that species is given by (Bouwer, 1991):

$$
R_{f}=V_{g w} / V_{s p}=1+\rho K_{d} / n
$$

where $V_{g w}$ is the velocity of groundwater, $V_{s p}$ is the velocity of the species, $\rho$ is the dry bulk density and $n$ is the porosity. If none of a particular species is lost to the solid phase, then $K_{d}=0$ and $R_{f}=1$ for that species. In column experiments, a breakthrough curve is 
obtained for the particular species and $R_{f}$ is determirıed as the pore volume at which $\mathrm{C} / \mathrm{C}_{\mathrm{o}}=0.5$. It is now genterally assumed that for unsaturated systems $n=\theta$ (Bouwer, 1991; Conca and Wright, 1992).

The UFA was used to determine the unsaturated retardation behavior of two Yucca Mountain tuffs with respect to J-13 well water spiked with selenite to $1.31 \mathrm{ppm} \mathrm{Se}$. Se concentrations were determined using a Jarrell-Ash Model 976 Plasma Atomcomp inductively coupled argon plasma atomic emission spectrometer. A Dionex Series 40()0i Ion Chromatograph was used to speciate the selenium. All selenium in the starting solutions and in all effluent solutions was found as $\mathrm{SeO}_{4}{ }^{-2}$ ion. For these experiments, the UFA rotation speed was set at $2000 \mathrm{rpm}$ with a flow rate of $0.2 \mathrm{ml} / \mathrm{hr}$ into each sample. The experiment was run for only 9 days. Figure 15 shows the breakthrough curves for selenite in the Yucca Mountain vitric member at $62.6 \%$ saturation, and in the zeolitized nonwelded tuff at $52.8 \%$ saturation. The unsaturated hydraulic conductivity during these retardation experiments was $2.49 \times 10^{-8} \mathrm{~cm} / \mathrm{s}$ for the Yucca Mountain vitric member and $1.16 \times 10^{-8} \mathrm{~cm} / \mathrm{s}$ for the zeolitized non-welded tuff. The experiment was stopped before full breakthrough in the zeolitized non-welded tuff, but the $C / C_{O}=0.5$ point was reached. The retardation factor for each tuff sample is only 2.5, giving a $K_{d}$ of 0.94 for the Yucca Mountain vitric member and 0.79 for the zeolitized non-welded tuff. These $K_{d} s$ are lower than expected from batch studies on similar materials (Thomas, 1987), but within an order of magnitude. Recent studies by J. Zachara and D. Rai of selenite sorption on various soils gave $K_{d}$ s between (0.()2 and 4.63 (Zachara, personal communication; manuscript in press) which are also fairly low, although consistently higher than selenate and sulfate $K_{d} s$ in the same materials. A possible explanation for the low $K_{d} s$ in the tuffs is that the adsorption isotherm for selenite is not linear in this high of a concentration range. Further retardation studies will be performed at $50 \mathrm{ppb}$ Se to examine this possibility.

\section{THE NEXT GENERATION UFA}

The existing UFA is the prototype instrument that has demonstrated that open-flow centrifugation is a useful investigative technique that should be used to compliment existing techniques for hydrologic characterization of any porous media, including rock. However, the prototype is not as easy and routine to operation as would be desirable. Therefore, the next-generation UFA has recently been built, and has a larger sample size capability (over twice times the present volume, or about 10() $\left.\mathrm{cm}^{3}\right)$; an improved fluid-dispersion system 


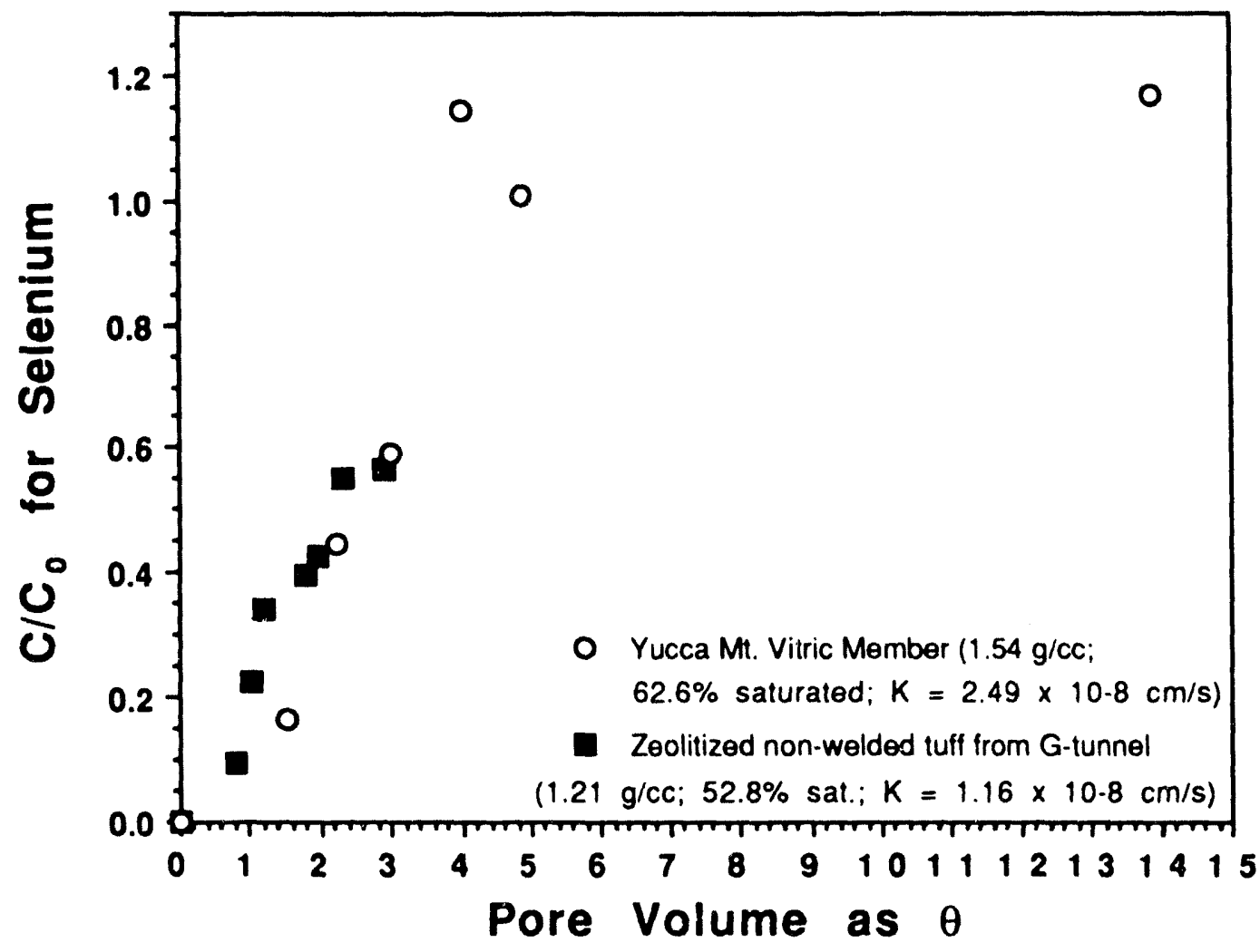

\section{Eigure 15. Yucca Mountain Tuff Retardation Experiment for $1.31 \mathrm{ppm}$ Selenium in J-13 Well Water as the Selenite Species}

that is built into the rotor for complete and homogeneous dispersion of fluids across the sample surface, including non-aqueous phase liquids; a new rotating seal that works more efficiently at high speeds; and easy quick-release mechanisms for sample removal and effluent collection. Different sample holders accommodate different sample sizes. As of this publication data, the new rotor has been built and is being tested. Thus far, it has performed well and results are identical between the prototype and the next-generation instrument.

\section{CONCLUSIONS}

Hydraulic conductivities, $K$, that were experimentally determined as a function of volumetric water content, $\theta$, in tuff from the Yucca Mountain site were used to determine the feasibility of applying a new unsaturated flow technique (UFA ${ }^{T M}$ ) to further hydrologic studies at Yucca Mountain. The UFA directly measures $K(\theta)$ rapidly in Yucca Mountain tuff and is shown to agree well with traditional methods. Hysteresis does not appear 
important during this testing. Capillary bundle theory holds in the UFA. Hydraulic steady-state is achieved fastest during desaturation from a saturated state. Imbibition into dry tuff requires a long time for steady-state :o occur because of slow filling of the diffusion porosity which can take a few weeks. The retardation factor for the selenite species was only 2.5 in Yucca Mountain vitric member at $62.6 \%$ saturation and zeolitized non-welded tuff from G-tunnel at $52.8 \%$ saturation with respect to $\mathrm{J}-13$ well water contaminated with selenium at $1.31 \mathrm{mg} / \mathrm{l}(\mathrm{ppm})$. The unsaturated hydraulic conductivity during these experiments for each sample was $2.49 \times 10^{-8} \mathrm{~cm} / \mathrm{s}$ for the Yucca Mountain vitric member and $1.16 \times 10^{-8} \mathrm{~cm} / \mathrm{s}$ for the zeolitized non-welded tuff. These preliminary investigations demonstrate that the UFA is a useful investigative technique that should be used to compliment existing techniques for hydrologic characterization at Yucca Mountain.

ACKNOWLEDGMENTS - The author would like to thank Lorrie Flint, Ines Triay, Alan Mitchell, Martin Ott, Judith Wright, Mike Fayer and Glendon Gee for materials, discussions and support.

\section{REFERENCES}

Albinsson, Y., and I. Engkvist. 1989. Diffusion of Am, Pu, U, Np, Cs, I and Tc in Compacted Sand-Bentonite Mixture, SKB Technical Report 89-22, Stockholm, Sweden.

Ashida, T., H. Sato, Y. Kohara, M. Yui, Y. Yusa, and N. Sasaki. 1993. Effect of Compacted Density on Diffusion of Radionuclides in Sodium Bentonite, Journal of Nuclear Science and Technology (in press).

Bresler, E., B. L. McNeal, and D. L. Carter. 1982. Saline and Sodic Soils, SpringerVerlag, New York.

Bouwer, H. 1991. Simple Derivation of the Retardation Equation and Application to Preferential Flow and Macrodispersion, Ground Water, v. 29, pp. 41-46.

Conca, J. L. and J. Wright. 1990. Diffusion Coefficients in Gravel Under Unsaturated Conditions, Water Resources Res. v. 26, pp. 1055-1066. 
Conca, J. L. and J. Wright. 1990. Effect of Meteoric Infiltration on the Aqueous Chemistry of Paintbrush Tuff During Exposure at the Surface, Radioactive Waste Management and the Nuclear Fuel Cycle. v. 15, pp. 27-41.

Conca, J. L. and Wright, J. V. 1992. Flow and Diffusion in Unsaturated Gravel, Soils and Whole Rock, Applied Hydrogeology. v. 1, pp. 5-24.

Conca, J. L. and J. V. Wright. 1992. A New Technology for Direct Measurements of Unsaturated Transport, Proceedings of the Nuclear and Hazardous Waste Management Spectrum '92 Meeting, American Nuclear Society, vol. 2, pp. 1546-1555.

Fayer, M., Pacific Northwest Laboratory, personal communication, April 1992.

Gee, G., Pacific Northwest Laboratory, personal communication, March 1991.

Kilbury, R. K., T. C. Rasmussen, D. D. Evans, and A. W. Warrick. 1986. Water and air intake to surface-exposed rock fractures in situ, Water Resources Res. v. 22, pp. 14311443.

Lin, W. and W. Daily. 1984. Transport Properties of Topopah Spring Tuff, UCRL-53602, Lawrence Livermore National Laboratories, Livermore, CA.

Montazer, P. 1987. Monitoring hydrologic conditions in the vadose zone in fractured rocks, in Flow and Transport Through Unsaturated Fractured Rock, D. D. Evans and T. J. Nicholson, editors, Geophysical Monograph 42, American Geophysical Union, Washington, D. C., pp. 31-43.

Nimmo, J. R., and K. C. Akstin. 1988. Hydraulic conductivity of a sandy soil at low water content after compaction by various methods, Soil Sci. Soc. Amer. J. v. 52, pp. 303-310.

Nimmo, J. R., and K. A. Mello. 1991. Centrifugal techniques for measuring saturated hydraulic conductivity, Water Resources Res. v. 27, pp. 1263-1269.

Nimmo, J. R., J. Rubin, and D. P. Hammermeister. 1987. Unsaturated flow in a centrifugal field: measurement of hydraulic conductivity and testing of Darcy's Law, Water Resources Res. v. 23, pp. 124-134.

Norton, D. and R. Knapp. 1977. Transport phenomena in hydrothermal sytems: the nature of porosity, American Journal of Science. v. 277, pp. 913-936. 
Oelkers, E. H. 1991. Calculation of Diffusion Coefficients for Aqueous Organic Species. Geochim. Cosmochim. Acta. v. 55, pp. 3515-3529.

Pigford, T. H. and P. L. Chambré. 1988. Near-field mass transfer in geologic disposal systems: a review, Mat. Res. Soc. Symp. Proc. v. 112, pp. 125-141.

Rai, D., and R. J. Serne, Solid Phases and Solution Species of Different Elements in Geologic Environments, PNL-2651, Pacific Northwest Laboratory, Richland, Washington, (1978).

Relyea, J. F., D. P. Trott, C. V. McIntyre, and C. G. Rieger. 1986. Diffusion of Tritiated Water and Chloride in Basalt-Bentonite Mixtures, Nuclear Technology. v. 74, pp. 317-323.

Robinson, R. A., and R. H. Stokes. 1959. Electrolyte Solutions, 2nd ed., Butterworths, London.

Russell, M. B., and L. A. Richards. 1938. The determination of soil moisture energy relations by centrifugation, Soil Sci.Soc. Amer. Proc. v. 3, pp. 65-69.

Stumm, W., and J. J. Morgan. 1981. Aquatic Chemistry, John Wiley \& Sons, New York.

Thomas, K. W. 1987. Summary of Sorption Measurements Performed with Yucca Mountain, Nevada, Tuff Samples and Water from Well J-13, LA-10960-MS, Los Alamos National Laboratory, Los Alamos, NM.

Wang, J. S. Y., and T. N. Narasimhan. 1993. Processes, Mechanisms, Parameters, and Modeling Approaches for Partially Saturated Flow in Soil and Rock Media. SAND887054. Sandia National Laboratories, Albuquerque, NM.

Wright, J. 1990. Diffusion Coefficients and Hydraulic Conductivity in Unsaturated Hanford Soils and Sediments. Proceedings of the First International High-Level Radioactive Waste Management Conference. v. 1, pp. 835-842.

Yang, I. C., A. K. Turner, T. M. Sayre, and P. Montazer. 1988. Triaxial-Compression Extraction of Pore Water from Unsaturated Tuff, Yucca Mountain, Nevada, WaterResources Investigation Report 88-4189, United States Geological Survey, Denver, Colorado.

Zachara, J., Pacific Northwest Laboratory, personal communication, June 1993. 

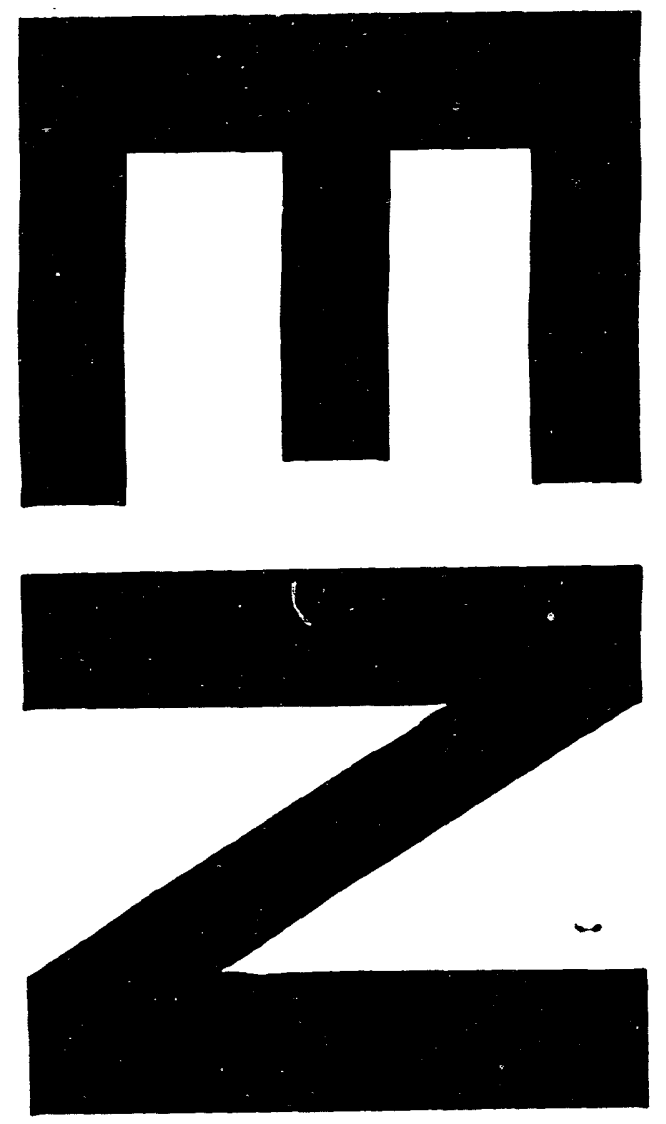

l
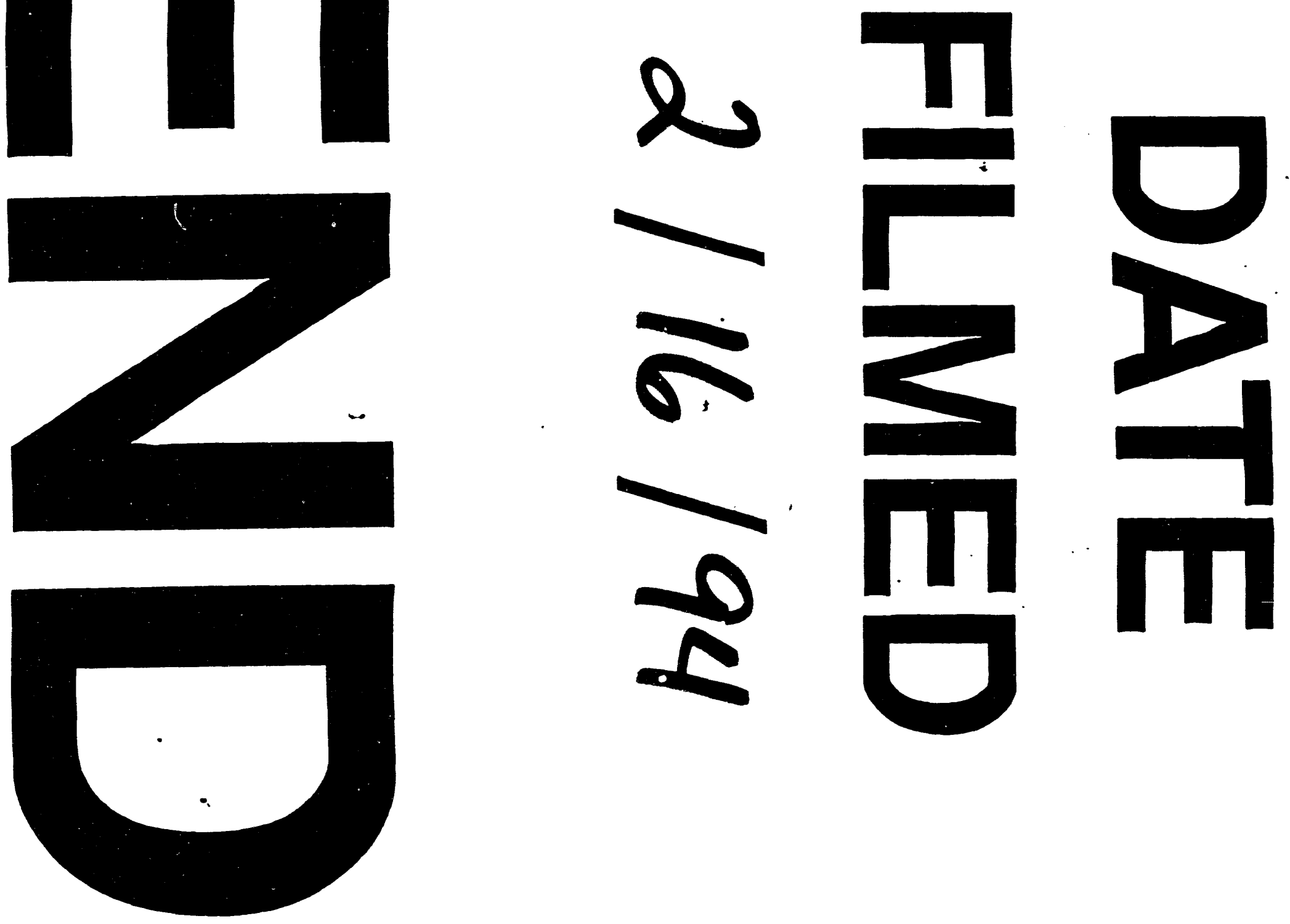

\&
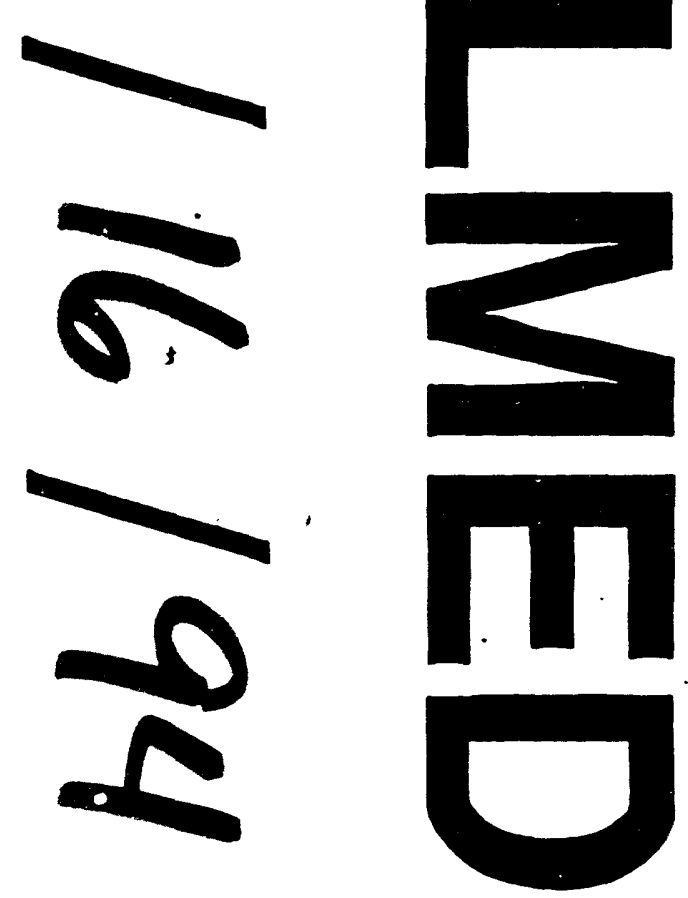
